\begin{tabular}{|c|l|}
\hline Title & A erodynamic Heating A round Flare Type Membrane Inflatable V ehicle in Suborbital Reentry Demonstration Flight \\
\hline Author(s) & Takahashi, Y usuke; Y amada, Kazuhiko; A be, Takashi; Suzuki, Kojiro \\
\hline Citation & $\begin{array}{l}\text { Journal of spacecraft and rockets, 52(6), 1530-1541 } \\
\text { https://doi.org/10.2514/1.A33170 }\end{array}$ \\
\hline Issue Date & 2015-11 \\
\hline Doc URL & http://hdl.handle.net/2115/60702 \\
\hline Rights & ○ 2015 A merican Institute of A eronautics and A stronautics \\
\hline Type & article (author version) \\
\hline File Information & journal_SMA AC-heatflux.pdf \\
\hline
\end{tabular}

Instructions for use 


\title{
Aerodynamic Heating around Flare-type Membrane Inflatable Vehicle in Suborbital Reentry Demonstration Flight
}

\author{
Yusuke Takahashi ${ }^{1}$ \\ Hokkaido University, Kita 13 Nishi 8, Kita-ku, Sapporo, Hokkaido, 060-8628, Japan, \\ Kazuhiko Yamada ${ }^{2}$, Takashi $\mathrm{Abe}^{3}$, \\ Japan Aerospace Exploration Agency, 3-1-1 Yoshinodai Chuo-ku, Sagamihara, Kanagawa \\ 252-5210, Japan \\ and \\ Kojiro Suzuki ${ }^{4}$ \\ The University of Tokyo, 5-1-5 Kashiwanoha, Kashiwa, Chiba, 277-8561, Japan
}

\begin{abstract}
A demonstration flight of an advanced reentry vehicle was carried out using a sounding rocket. The vehicle was equipped with a flexible (membrane) aeroshell deployed by an inflatable torus structure. Its most remarkable feature was the low ballistic coefficient that enables reduction in aerodynamic heating and deceleration at a high altitude. During the suborbital reentry, temperatures at several locations on a backside of the flexible aeroshell and inside the capsule were measured by means of embedded thermocouples. The aerodynamic heating behavior of the vehicle was investigated using the measured temperature history, in combination with a numerical prediction in which a flow-field simulation of the heating was conducted. In this flow-field simulation, both laminar flow and turbulent flow were assumed, and the deformation of the flexible aeroshell was considered. A thermal model of the capsule and membrane aeroshell was developed, and the heat flux profiles of the vehicle surface during aerodynamic heating were constructed based on the measured temperatures. The measured temperature data were found to be in reasonable agreement with the predicted data if the flow field near the capsule of the vehicle was assumed to be laminar, with a transition to turbulent flow near the membrane aeroshell.
\end{abstract}

\section{Nomenclature}

$\begin{array}{lll}a & = & \text { coefficient } \\ C_{p} & = & \text { specific heat at constant pressure, } \mathrm{J} /(\mathrm{kg} \cdot \mathrm{K}) \\ E & = & \text { Young's modulus, } \mathrm{Pa} \\ h & = & \text { heat transfer coefficient } \mathrm{W} /\left(\mathrm{m}^{2} \cdot \mathrm{K}\right), \text { or membrane thickness, } \mathrm{m} \\ I_{\text {solar }} & = & \text { solar constant, } \mathrm{W} / \mathrm{m}^{2} \\ k & = & \text { turbulent kinetic energy } \mathrm{J} / \mathrm{kg} \\ l, L & = & \text { length, } \mathrm{m} \\ \mathrm{ns} & = & \text { number of species } \\ \mathrm{nm} & = & \text { number of molecules } \\ \mathrm{Nu} & = & \text { Nusselt number } \\ p & = & \text { pressure, } \mathrm{Pa}\end{array}$

\footnotetext{
${ }^{1}$ Assistant Professor, Faculty of Engineering; ytakahashi@eng.hokudai.ac.jp.

${ }^{2}$ Assistant Professor, Institute of Space and Astronautical Science.

${ }^{3}$ Professor, Institute of Space and Astronautical Science.

${ }^{4}$ Professor, Graduate School of Frontier Sciences.
} 


$\begin{array}{lll}\mathrm{Pr} & = & \text { Prandtl number } \\ q & = & \text { heat flux, } \mathrm{W} / \mathrm{m}^{2} \\ R & = & \text { gas constant, } \mathrm{J} / \mathrm{kg} \cdot \mathrm{K}) \\ \operatorname{Re} & = & \text { Reynolds number } \\ \mathbf{r} & = & \text { position vector, } \mathrm{m} \\ S & = & \text { membrane area, } \mathrm{m}^{2} \\ t & = & \text { time, } \mathrm{s} \\ T & = & \text { temperature, } \mathrm{K} \\ U & = & \text { velocity, } \mathrm{m} / \mathrm{s} \\ \varepsilon & = & \text { emissivity, or strain } \\ \Theta_{\mathrm{vib}, s} & = & \text { vibrational characteristic temperature, } \mathrm{K} \\ \kappa & = & \text { Heat conductivity, W/(m } \cdot \mathrm{K}) \\ \rho & = & \text { density, } \mathrm{kg} / \mathrm{m}^{3} \\ \mu & = & \text { viscosity, Pa } \cdot \mathrm{S} \\ \nu & = & \text { Poisson's ratio } \\ \sigma & = & \text { Stefan-Boltzmann constant } \\ \text { Subscripts } & \\ \text { atm } & = & \text { atmosphere } \\ \mathrm{b} & = & \text { background } \\ \text { conv } & = & \text { convection } \\ \text { solar } & = & \text { solar } \\ \mathrm{t} & = & \text { turbulent } \\ \infty & = & \text { freestream }\end{array}$

\section{Introduction}

A reentry vehicle with a membrane aeroshell deployable by an inflatable torus structure is a candidate for a next generation space transport system. The main feature of note for this kind of vehicle, which was originally proposed in the 1960s, is the low ballistic coefficient during atmospheric reentry. Since then, several studies and demonstration flights have been performed by the National Aeronautics and Space Administration (NASA), the European Space Technology (ESA), and the Japan Aerospace Exploration Agency (JAXA). In general, the use of a deployable aeroshell allows the vehicle to be decelerated at a higher altitude compared with a conventional rigid reentry vehicle. This provides several advantages for the entry, descent, and landing (EDL) approach, such as a lower heat load from aerodynamic heating and reduction in radio-frequency blackout [1-9].

Recently, a reentry vehicle with an inflatable aeroshell has also been developed in the Membrane Aeroshell for Atmospheric-entry Capsule (MAAC) project, in cooperation with several universities and JAXA. In the considered reentry mission, a capsule with a tightly packed aeroshell, e.g., a slender cylinderical shape, is first transported to a given orbit. As the torus tube is inflated, the vehicle rapidly expands the membrane aeroshell under vacuum and microgravity conditions. After deployment, the flare-type membrane aeroshell is sustained by an inflatable torus. It should be noted that the deployed aeroshell later plays roles as a parachute and float after splashing. Then, the vehicle is kicked into an atmospheric reentry orbit. Because of the large area and light weight of the aeroshell, the vehicle can achieve a low-ballistic-coefficient flight during atmospheric reentry. This kind of inflatable 
deceleration system may not require a parachute because of its low terminal velocity upon landing. Additionally, because the aeroshell deployment is accomplished before deorbit, a critical operation, such as parachute extraction, is possibly dispensed in exchange for the use of the inflatable vehicle during the EDL approach.

Some studies and the development of elemental technologies for a future inflatable vehicle have been experimentally and numerically performed as part of the MAAC project. The basic concept of a low-ballistic-coefficient flight for the MAAC results in a reduction in the aerodynamic heating. This directly contributes to a decrease in the heat flux on the surface of the vehicle. Free flight tests using a scientific balloon were performed in 2004 and 2009 [10,11]. In addition, JAXA's hypersonic wind tunnel coupled with a numerical simulation approach was used to evaluate the aerodynamic heating in front of an inflatable vehicle [12]. The structural strength of a membrane aeroshell was examined using JAXA's low-speed wind tunnel [13]. Because the plasma behind the shock wave becomes weak due to the lowballistic-coefficient flight, the possibility of vehicle-to-ground-station communication increases compared with a conventional capsule. In Ref. [14,15], the behavior of the electromagnetic waves around the vehicle during atmospheric reentry was numerically investigated, and the reduction or avoidance of radio frequency $(\mathrm{RF})$ blackout was indicated. Important milestones in the MAAC project include a reentry demonstration using a sounding rocket [16] (SMAAC: Sounding Rocket Experiment of Membrane Aeroshell for Atmospheric-Entry Capsule). This mission was a demonstration to clarify the low-ballistic-coefficient flight of a kind of inflatable vehicle during reentry. On August 8, 2012, a suborbital reentry demonstration of the SMAAC inflatable vehicle was successfully performed using a JAXA/ISAS S-310-41 sounding rocket [17-20].

Figure 1 shows a photograph of the SMAAC before the flight experiment. In the demonstration flight, the reentry vehicle (a capsule with an inflatable aeroshell) was separated from the rocket at an altitude of $110 \mathrm{~km}$ and started to re-enter from an altitude of about $150 \mathrm{~km}$. The vehicle achieved a maximum velocity of $1320 \mathrm{~m} / \mathrm{s}$, Mach number of 4.5, and dynamic pressure of $500 \mathrm{~Pa}$ according to Ref. [17]. The temperatures on the back side of the membrane part and the capsule part of the SMAAC vehicle were measured by means of thermocouples and transmitted to a ground base station during the flight.

For the development of an inflatable vehicle, it is important to evaluate the measured temperature and understand the aerodynamic heating environment of the vehicle during atmospheric reentry. Compared with conventional reentry capsules, an inflatable vehicle is larger, and the membrane aeroshell is deformed by the aerodynamic force. Hence, it is important to clarify the thermal behavior of the vehicle with membrane deformation during aerodynamic heating. In addition, the Reynolds number is $\mathrm{O}\left(10^{4}\right)$ to $\mathrm{O}\left(10^{5}\right)$, and it is possible that partial or total turbulent transition of the flow field will occur around the SMAAC. Because there is a large heat flux difference between the laminar and turbulent flow cases, it is important to understand the flow field characteristics for future designs. In the present paper, we focus on the temperature histories obtained inside the capsule and on the membrane aeroshell. The aerodynamic heating behavior of the SMAAC is investigated and discussed based on the measured temperatures in combination with numerical prediction technique. The research objectives also include the reconstruction of the aerodynamic heating prediction for the inflatable vehicle during reentry. 


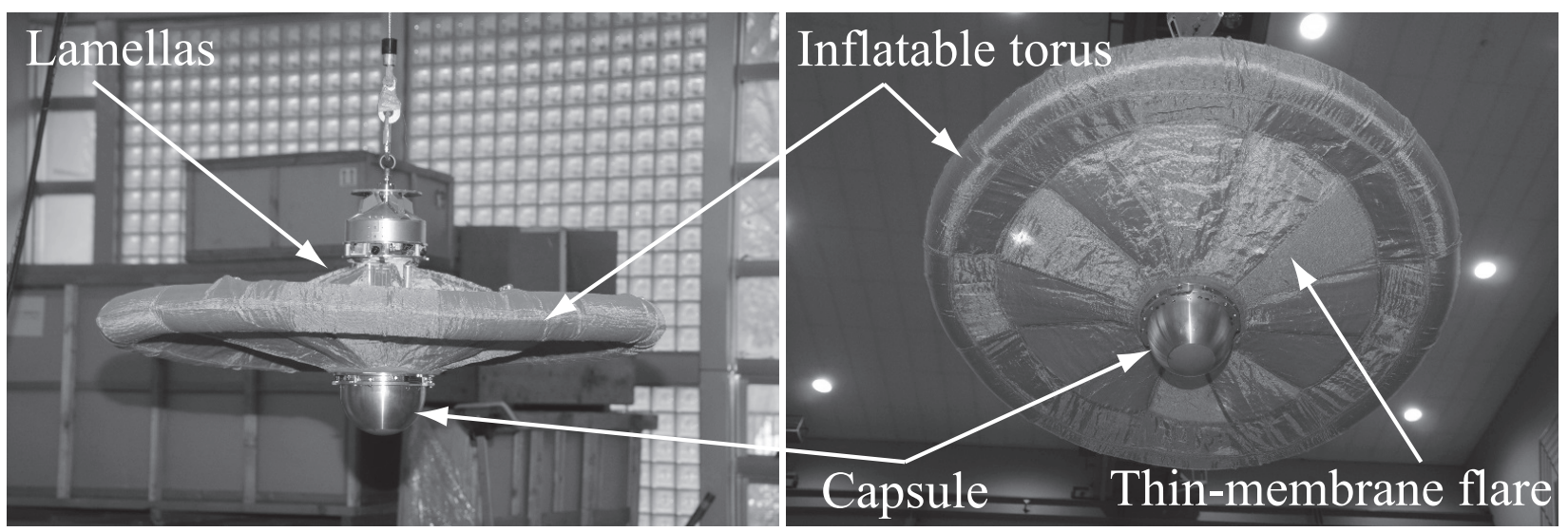

Figure 1: Photographs of the SMAAC.

\section{Experiment}

\subsection{SMAAC reentry vehicle}

The SMAAC mainly consists of three components, i.e., the capsule, membrane aeroshell, and inflatable torus. Figure 2 shows the configuration (left side) of the SMAAC and the mounting positions of the thermocouples on the aeroshell (right side: backside view). The capsule has a semi-spherical configuration, with a diameter of $190 \mathrm{~mm}$. The membrane aeroshell has a flare angle of $70^{\circ}$ and a frontal projected diameter of $910 \mathrm{~mm}$, and connects to the inflatable torus. The inflatable torus has a tube diameter of $100 \mathrm{~mm}$. After being inflated, the overall diameter of the vehicle is $1200 \mathrm{~mm}$. Note that the diameter becomes $1250 \mathrm{~mm}$ when the torus is sufficiently pressurized. The profiles of ballistic and drag coefficients are shown in Fig. 3 [17], where the mass and diameter of the SMAAC is $15.6 \mathrm{~kg}$ and $1250 \mathrm{~mm}$, respectively. The ballistic coefficient in the supersonic region is approximately $8.5 \mathrm{~kg} / \mathrm{m}^{2}$, and it increases in the subsonic region. The primary fabric used for the aeroshell membrane and inflatable torus is ZYLON, ${ }^{5}$ which has a high thermal durability and high tensile strength. Note that silicone is also used inside the inflatable torus. The decomposition temperature of ZYLON is approximately $800 \mathrm{~K}$; however, ZYLON is sensitive to ultraviolet light. During reentry, the duration of sunlight exposure is short because of the packing of the aeroshell; thus it is possible to reduce the effects of the ultraviolet light. The capsule part consists of an antenna cover, aluminum capsule, and antenna, which is fixed in place by a brass plate. The material of the antenna cover is Cepla ${ }^{6}$ which is a kind of polyimide resin and is widely used for heat resistance. Backside views of the antenna cover and aluminum capsule are shown in Figs. 4(a) and 4(b), respectively. The antenna cover is basically a spherical cap with a base radius of $50 \mathrm{~mm}$, while the aluminum capsule is a semi-spherical shell from which the cap is separated.

\section{$2.2 \quad$ Flight sequence and reentry trajectory}

The reentry trajectory of the SMAAC was evaluated by Yamada et al. [18] and the measured orbit was confirmed to be in agreement with the preliminary predicted profile. The SMAAC

\footnotetext{
${ }^{5}$ Toyobo Corporation, ZYLON technical data, http://www.toyobo-global.com/seihin/kc/pbo/

${ }^{6}$ Suzuko Corporation, Cepla technical data, http://www.suzuko.co.jp/english/original/cepla1.html
} 


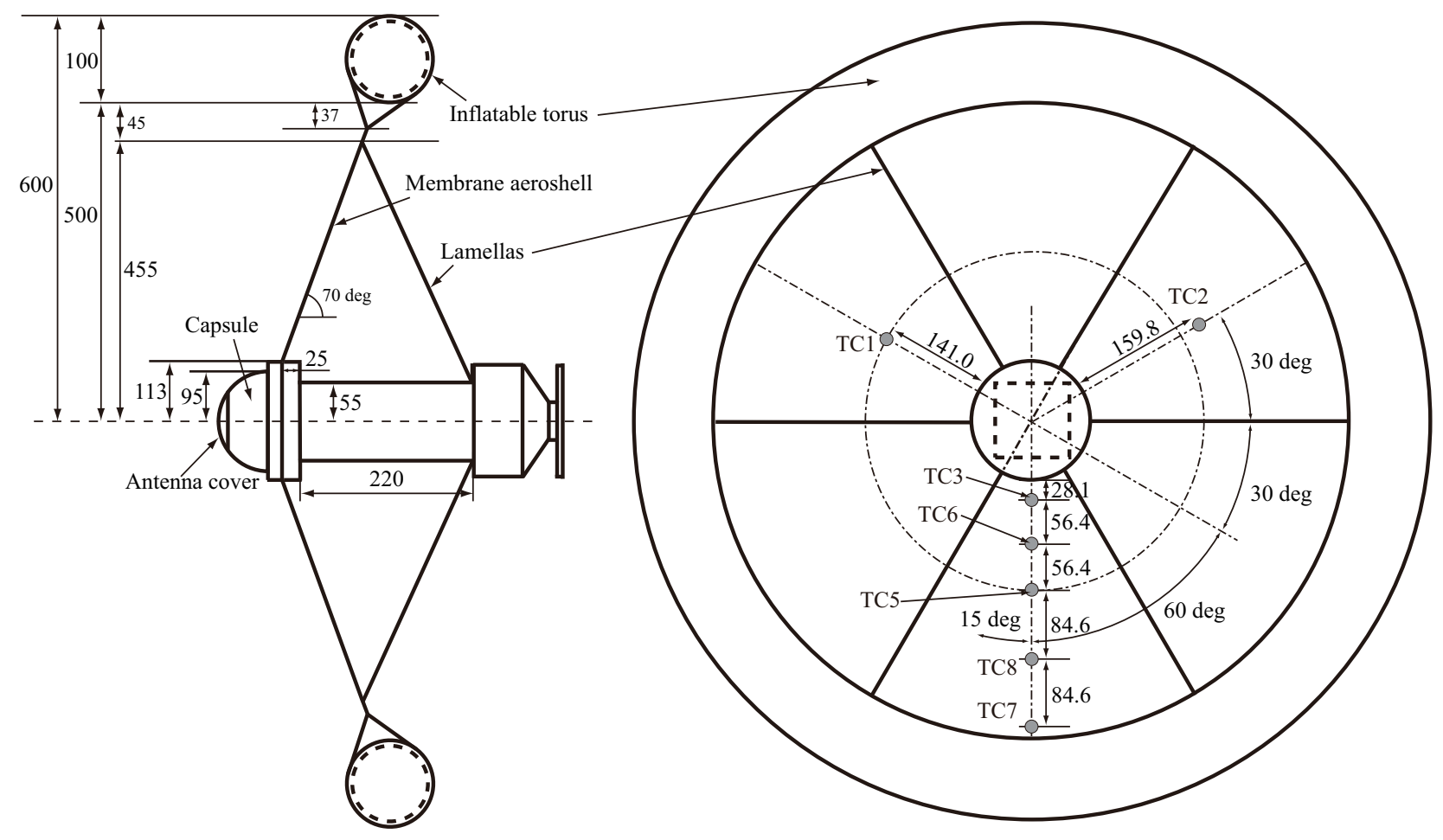

Figure 2: SMAAC configuration and mounting positions of thermocouples (all dimensions are in millimeters).

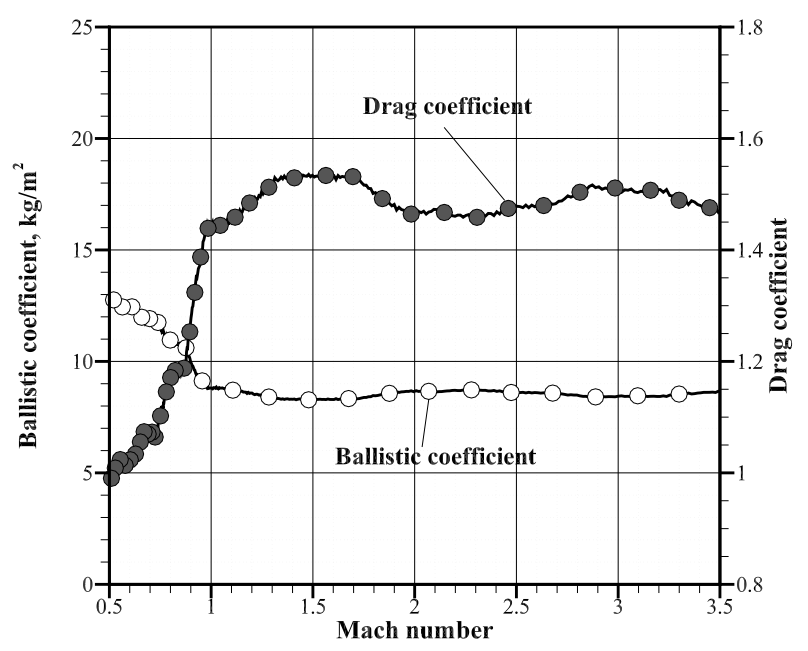

Figure 3: Profiles of SMAAC ballistic and drag coefficients. 


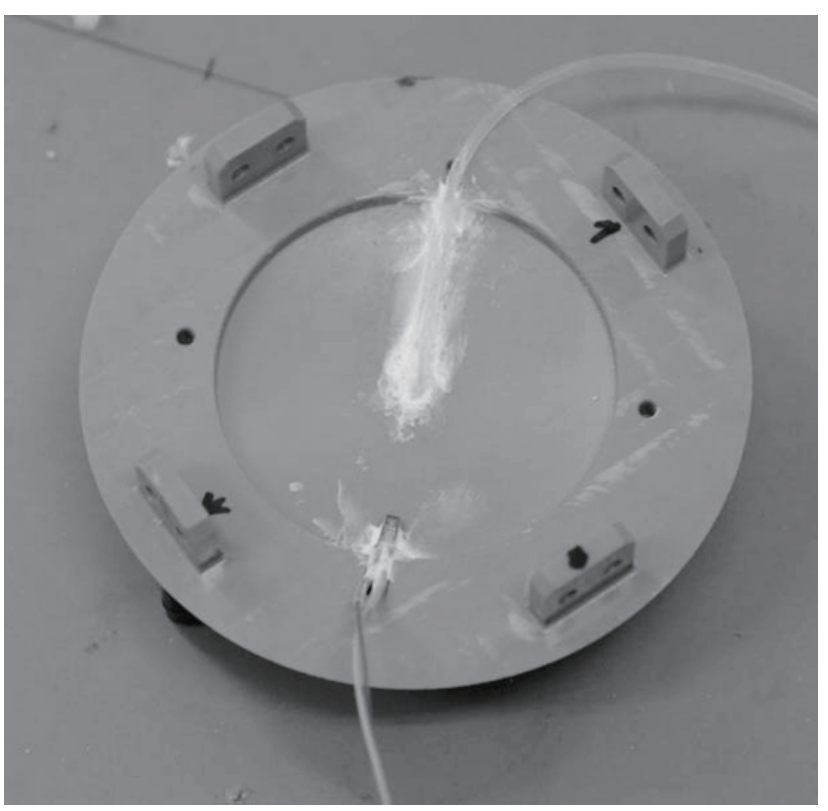

(a) Antenna cover.

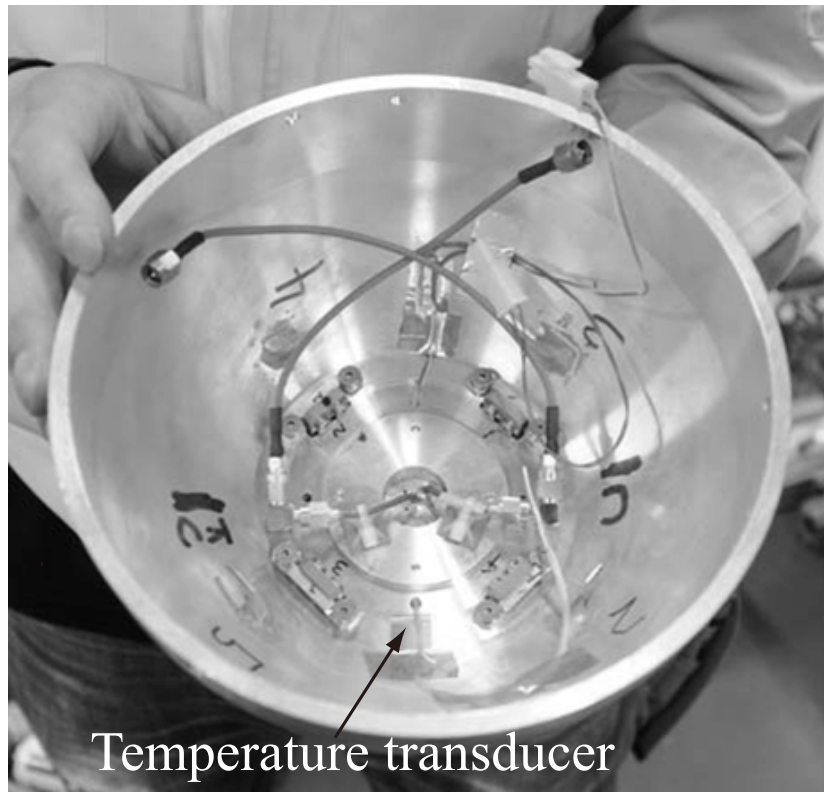

(b) Aluminum capsule.

Figure 4: Backside view of capsule part.

vehicle was launched by the S-310-41 sounding rocket in August 8, 2012, at the Uchinoura space center, Kagaoshima, Japan. The aeroshell cover of the vehicle was opened at an altitude of $100 \mathrm{~km}$, and the inflatable torus was pressurized at $106 \mathrm{~km}$ to deploy the membrane aeroshell. Then, the vehicle was separated from the rocket at an altitude of $111 \mathrm{~km}$. The vehicle started to reentry the Earth's atmosphere at an altitude of $150 \mathrm{~km}$. The vehicle had an angular velocity of $1.2 \mathrm{~Hz}$ around the body axis (in the roll direction) when separated from the rocket. The profile of the reentry trajectory of the SMAAC is shown in Fig. 5. This figure shows the altitude, reentry velocity, and dynamic pressure versus the elapsed time after launch. The standard atmospheric model, GRAM99 [21], was used to evaluate the density and temperature of air during reentry. The peak reentry velocity was approximately 1320 $\mathrm{m} / \mathrm{s}$ at an altitude of $66 \mathrm{~km}$ during the experiment. At an altitude of $58 \mathrm{~km}$, the heat flux at the stagnation point of the capsule was expected to reach a maximum value. The dynamic pressure rapidly increased at an altitude of $60 \mathrm{~km}$ and reached a maximum value of $500 \mathrm{~Pa}$ at an altitude of $50 \mathrm{~km}$. Then, the acceleration almost became zero below $23 \mathrm{~km}$ (500 s later after launch), and the vehicle continued to fly with a terminal velocity of $15 \mathrm{~m} / \mathrm{s}$. Finally, the vehicle splashed down and sank in the Pacific Ocean.

\subsection{Temperature measurement}

The temperature profiles at the backside of the aluminum capsule were measured with a temperature transducer (2-terminal IC temperature transducer, Analog Devices, Inc., AD590). The temperature transducer of the aluminum capsule was mounted at a $45^{\circ}$ angle on the backside of the semi-spherical shell of the capsule, as shown in Fig. 4(b).

To measure the temperatures at various positions on the aeroshell during atmospheric reentry, seven thermocouples (type K thermocouple, Fukuden Incorporated, K-CCBF) were embedded on the back-side of the membrane (TC1-TC3, TC5-TC8), as shown in Fig. 2. As shown in Fig. 6, the thermocouples were wrapped in a kapton film and mounted on the membrane aeroshell, which was made of ZYLON filament fabric (LZY0530W, Toyobo 


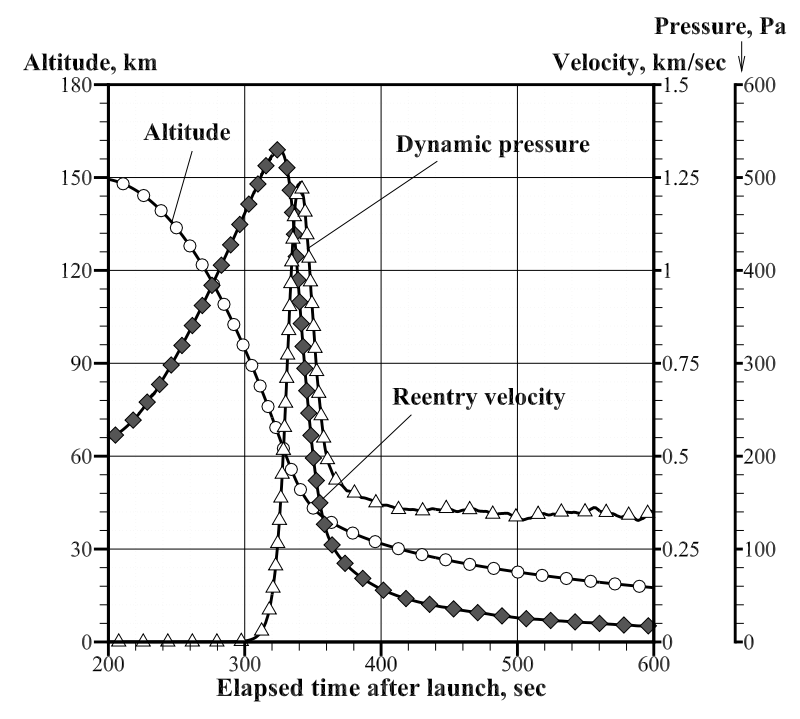

Figure 5: Trajectory profile of SMAAC mission

Corporation, $0.15 \mathrm{~mm}$ thick, with an area density of $135 \times 10^{-3} \mathrm{~kg} / \mathrm{m}^{2}$ ), being sandwiched between two ZYLON yarn covers (DA4220W, Toyobo Corporation, $0.37 \mathrm{~mm}$ thick, with an area density of $330 \times 10^{-3} \mathrm{~kg} / \mathrm{m}^{2}$ ). Because the thermocouples were sandwiched by the ZYLON yarn covers, the membrane containing the thermocouples had a thickness of 0.89 $\mathrm{mm}$.

\section{Numerical prediction}

The measured temperature data can be analyzed using heat conduction simulations at each location based on the simulated flow field.

\subsection{Heat conduction model}

To analyze the thermal behaviors of the capsule part and membrane aeroshell, heat conduction models are introduced. Here, we basically use an unsteady heat conduction equation to describe the temperature change and distribution. This heat conduction equation is expressed in general form as follows:

$$
\frac{\partial\left(\rho C_{p} T\right)}{\partial t}=\frac{\partial}{\partial x_{j}}\left(\kappa \frac{\partial T}{\partial x_{j}}\right)
$$

where $T, \rho, C_{p}, t$, and $\kappa$ are the temperature, density, specific heat, time, and heat conductivity, respectively. As the inlet condition of the heat at the boundary, in addition to the aerodynamic heating and blackbody radiation, one considers the heat fluxes of the solar radiation and the forced convection, which play important roles at higher and lower altitudes, respectively. Table 1 lists the membrane thickness at the thermocouples positions and the material properties used in the capsule and membrane aeroshell. Because the capsule and membrane parts have different features, it is reasonable to use different assumptions and models. In the following subsections, the heat conduction models of the capsule and membrane aeroshell are defined. 

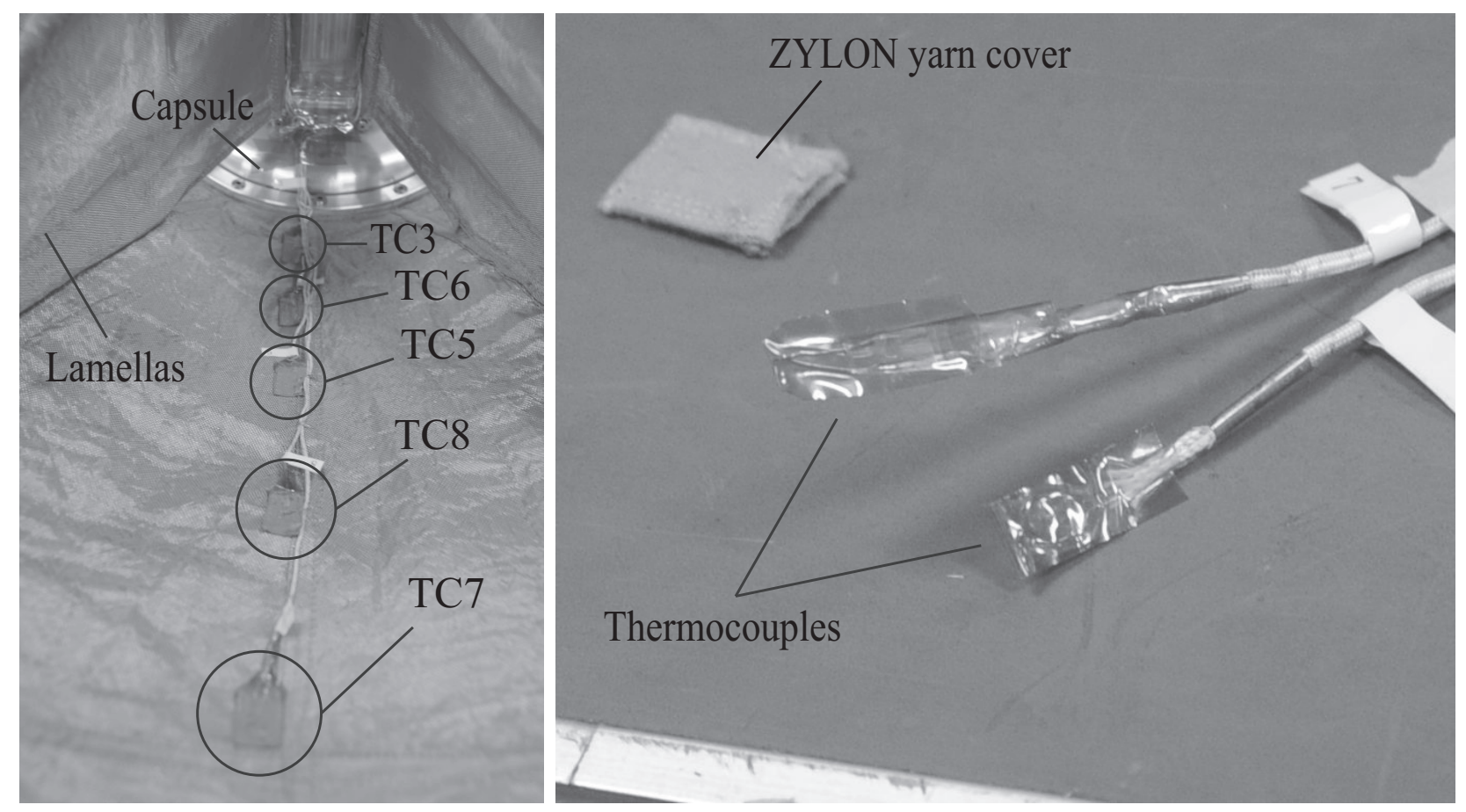

Figure 6: Thermocouples.

Table 1: Material properties of capsule part and membrane aeroshell.

\begin{tabular}{c|cccc}
\hline \hline & Cepla & Aluminum & Brass & ZYLON \\
\hline Thickness at thermocouples $(l), \mathrm{mm}$ & - & - & - & 0.89 \\
Density $(\rho), \mathrm{kg} / \mathrm{m}^{3}$ & 1400 & 2700 & 8560 & 900 \\
Specific heat $\left(C_{p}\right), \mathrm{J} / \mathrm{kg} \cdot \mathrm{K}$ & 1050 & 900 & 385 & 1000 \\
Heat conductivity $(\kappa), \mathrm{W} / \mathrm{m} \cdot \mathrm{K}$ & 0.290 & 237 & 106 & 0.2 \\
Emissivity $(\varepsilon)$ & 0.9 & 0.3 & 0.1 & 0.9 \\
\hline \hline
\end{tabular}




\subsubsection{Capsule part}

Because the capsule part has basically an axisymmetric configuration, the two-dimensional axisymmetric form of Eq. (1) is used. At the inlet boundary, the heat flux on the vehicle surface is given by

$$
Q= \begin{cases}q_{\mathrm{conv}}-\varepsilon \sigma\left(T^{4}-T_{\mathrm{b}}^{4}\right)+a_{\text {solar }} I_{\text {solar }}, & \text { during aerodynamic heating; } \\ -\varepsilon \sigma\left(T^{4}-T_{\mathrm{b}}^{4}\right)+a_{\text {solar }} I_{\text {solar }}-h\left(T-T_{\mathrm{atm}}\right), & \text { otherwise }\end{cases}
$$

where $q_{\text {conv }}$ is the convective heat flux on the capsule surface by aerodynamic heating; and $\varepsilon, \sigma, I_{\text {solar }}, h$, and $T_{\text {atm }}$ are the emissivity, Stefan-Boltzmann constant, solar constant, heat transfer coefficient, and atmospheric temperature, respectively. The SMAAC flies at certain angle to the solar rays, and there is reflection on the membrane surface. Thus, the coefficient $\left(a_{\text {solar }}\right)$ is multiplied to evaluate the net solar radiation. In the calculation, $a_{\text {solar }}$ is simply set to 0.25 . The forced convection term appears at altitude, except for the aerodynamic heating duration. The heat transfer coefficient is given by

$$
\begin{gathered}
h=\frac{\mathrm{Nu} \kappa_{\text {atm }}}{L}, \\
\mathrm{Nu}=2+\left(0.4 \operatorname{Re}^{1 / 2}+0.06 \operatorname{Re}^{2 / 3}\right) \operatorname{Pr}^{0.4}\left(\frac{\mu}{\mu_{s}}\right)^{1 / 4} .
\end{gathered}
$$

where $\mathrm{Nu}, \kappa_{\text {atm }}$, and $L$ are respectively the Nusselt number, heat conductivity of air, and characteristic length of SMAAC; and Re, $\operatorname{Pr}$, and $\mu_{s}$ are the Reynolds number, Prandtl number, and viscosity at the capsule surface, respectively. The background temperature $\left(T_{\mathrm{b}}\right)$ is given based on Ref [22].

Figure 7(a) shows the computational grid system for the heat conduction model of the capsule. The heat conduction equation in the capsule part is solved using a multi-block method. At each block interface, information about the properties between two blocks is exchanged at each time step. Figure $7(\mathrm{~b})$ shows the computational domain and boundary conditions. At the inlet, the heat fluxes based on the aerodynamic heating, blackbody radiation, solar radiation, and forced convection are given. An axisymmetric condition is imposed along the center axis. Adiabatic conditions are imposed at the backsides of the antenna cover and aluminum capsule. An initial temperature of $295 \mathrm{~K}$ is given based on the measured data when being separated from the sounding rocket.

\subsubsection{Membrane part}

No temperature gradient in the thickness direction is assumed because the membrane is relatively thin. Thus, the membrane temperature predicted herein is an averaged value in the thickness direction. The zero-dimensional form in the spatial direction of Eq. (1) is used.

$$
\frac{\partial\left(\rho C_{p} T\right)}{\partial t}=\dot{Q}
$$

Blackbody radiations on the front and back sides of the membrane are considered. The background temperatures $T_{\mathrm{b}}$ are the same at the two sides. At the inlet boundary, the heat flux on the membrane surface is slightly different from that of the capsule part, which is given by

$$
Q= \begin{cases}q_{\mathrm{conv}}-2 \varepsilon \sigma\left(T^{4}-T_{\mathrm{b}}^{4}\right)+a_{\text {solar }} I_{\text {solar }}, & \text { during aerodynamic heating; } \\ -2 \varepsilon \sigma\left(T^{4}-T_{\mathrm{b}}^{4}\right)+a_{\mathrm{solar}} I_{\text {solar }}-2 h\left(T-T_{\mathrm{atm}}\right), & \text { otherwise. }\end{cases}
$$




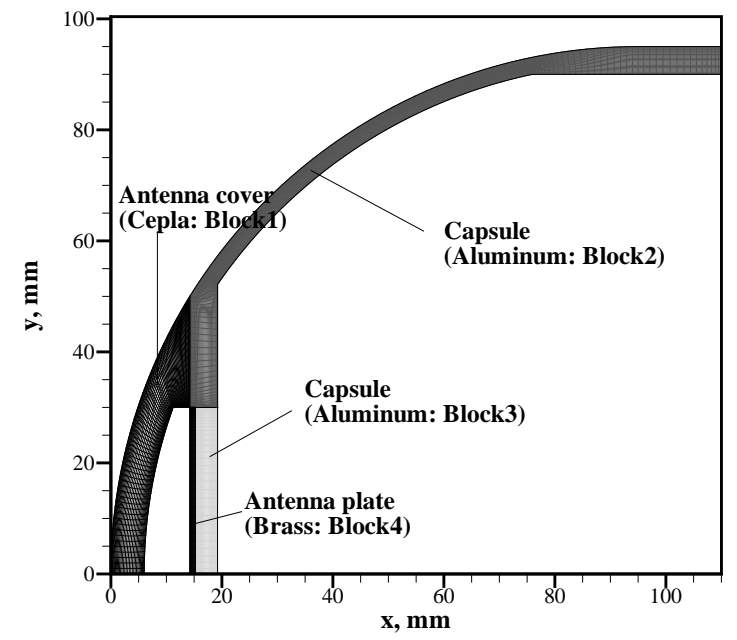

(a) Computational grid system.

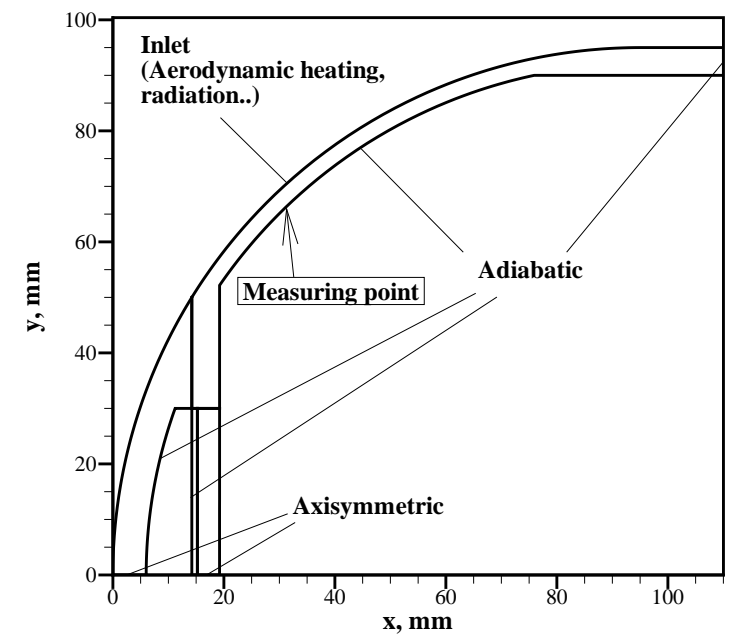

(b) Computational domain and boundary conditions.

Figure 7: Computational conditions of heat conduction model for capsule part

The model parameters of Eq. (6) are the same as those of Eq. (2), except for the Nusselt number, which is evaluated by the following expression:

$$
\mathrm{Nu}= \begin{cases}0.664 \operatorname{Re}^{1 / 2} \operatorname{Pr}^{1 / 3}, & \text { if } \operatorname{Re}<10^{5} \\ 0.037 \operatorname{Re}^{4 / 5} \operatorname{Pr}^{1 / 3}, & \text { if } \operatorname{Re} \geq 10^{5}\end{cases}
$$

Note that the time scale $\left(t=\rho C_{p} / \kappa\right)$ of the heat conduction of the membrane in the thickness direction is approximately $3.6 \mathrm{~s}$ from Table 1.

\subsection{Flow field model}

Unlike the flow field simulation for a conventional reentry vehicle, it is important to consider the deformation of the inflatable aeroshell in the flow field simulation for the inflatable reentry vehicle.

\subsubsection{Governing equations}

In this paper, the following assumptions are employed. (1) The flow is laminar or turbulent, steady, continuum, and axisymmetric. (2) The inflow gas is air. (3) No chemical reaction occurs. (4) The translation, rotation, and vibration modes of internal energy freedom are considered, while each temperature is equilibrated.

The flow field is described by the Navier-Stokes equations and the equation of state. The considered gases are molecular nitrogen and oxygen $(\mathrm{ns}=\mathrm{nm}=2)$. The Navier-Stokes equations are composed of the total mass, momentum, and total energy conservations, which 
can be expressed as follows:

$$
\begin{aligned}
& \frac{\partial \rho}{\partial t}+\frac{\partial}{\partial x_{j}}\left(\rho u_{j}\right)=0 \\
& \frac{\partial\left(\rho u_{j}\right)}{\partial t}+\frac{\partial}{\partial x_{j}}\left(\rho u_{i} u_{j}+\delta_{i j} p\right)=\frac{\partial \tau_{i j}}{\partial x_{j}}, \\
& \frac{\partial E}{\partial t}+\frac{\partial}{\partial x_{j}}\left[(E+p) u_{j}\right]=\frac{\partial}{\partial x_{j}}\left(u_{j} \tau_{i j}\right)+\frac{\partial q_{j}}{\partial x_{j}}
\end{aligned}
$$

where $\delta_{i j}$ is the Kronecker delta. Furthermore, $\tau_{i j}$ and $q_{j}$ are the stress tensor and heat flux, which are, respectively, given by

$$
\begin{aligned}
\tau_{i j} & =\left(\mu+\mu_{\mathrm{t}}\right)\left(\frac{\partial u_{i}}{\partial x_{j}}+\frac{\partial u_{j}}{\partial x_{i}}-\frac{2}{3} \frac{\partial u_{k}}{\partial x_{k}} \delta_{i j}\right)-\frac{2}{3} \rho k \delta_{i j}, \\
q_{j} & =\left(\lambda+\lambda_{\mathrm{t}}\right) \frac{\partial T}{\partial x_{j}} .
\end{aligned}
$$

The equation of state can be expressed as

$$
p=\sum_{s=1}^{\mathrm{ns}} \rho_{s} R_{s} T=\rho \hat{R} T
$$

The total energy $E$ is given by

$$
E=\sum_{s=1}^{\mathrm{ns}} \frac{5}{2} \rho_{s} R_{s} T+\sum_{s=1}^{\mathrm{nm}} \frac{\rho_{s} R_{s} \Theta_{\mathrm{vib}, s}}{\exp \left(\Theta_{\mathrm{vib}, s} / T\right)}+\frac{1}{2} \rho u_{j} u_{j}+\rho k,
$$

where $\Theta_{\text {vib,s }}$ is the vibrational characteristic temperature. Transport properties, such as viscosity and thermal conductivity, are evaluated by Yos' formula [23], which is based on the first Chapman-Enskog approximation. The collision cross sections are given by Gupta [24]. As a turbulence model, the shear stress transport (SST) turbulence model [25] is adopted. The turbulent kinetic energy $k$ and the turbulent viscosity $\mu_{\mathrm{t}}$ in Eq. (11) can be obtained with the SST turbulence model. The turbulent heat conductivity $\lambda_{\mathrm{t}}$ in Eq. (12) is evaluated using the turbulent Prandtl number $P r_{\mathrm{t}}$ and the specific heat at constant pressure $C_{p}$ as $\lambda_{\mathrm{t}}=C_{p} \mu_{\mathrm{t}} / P r_{\mathrm{t}}$. In the present study, $P r_{\mathrm{t}}$ was set to 0.9 .

The governing equations are transformed for a generalized coordinate system and are solved using a finite volume approach. All the flow properties are set at the center of a control volume. The inviscid fluxes in the flow-field equations are evaluated using the SLAU scheme [26], and all the viscous terms are calculated using the second-order central difference method. The spatial accuracy is thus essentially second order. Time integration is performed using an implicit time-marching method. The governing equation system is transformed into the delta form, and the solution is updated at each time step. We employ the lower-upper symmetric Gauss-Seidel (LU-SGS) method [27].

\subsubsection{Boundary and calculation conditions}

At the inflow, the freestream parameters are given following the orbit data [18]. As outflow conditions, all the flow properties are determined by the zeroth extrapolation, because the flow was supersonic in most regions. The non-slip condition for the velocity is imposed at 
Table 2: Calculation conditions.

\begin{tabular}{|c|c|c|c|c|c|c|c|c|c|c|c|c|c|c|}
\hline Elapsed time, s & \multicolumn{2}{|c|}{301} & \multicolumn{2}{|c|}{304} & \multicolumn{2}{|c|}{308} & \multicolumn{2}{|c|}{312} & \multicolumn{2}{|c|}{316} & \multicolumn{2}{|c|}{324} & 328 & 332 \\
\hline Altitude, km & \multicolumn{2}{|c|}{94.0} & \multicolumn{2}{|c|}{90.1} & \multicolumn{2}{|c|}{86.0} & \multicolumn{2}{|c|}{82.0} & \multicolumn{2}{|c|}{77.0} & \multicolumn{2}{|c|}{68.1} & 63.0 & 58.9 \\
\hline Velocity, m/s & \multicolumn{2}{|c|}{1159.3} & \multicolumn{2}{|c|}{1191.0} & \multicolumn{2}{|c|}{1220.8} & \multicolumn{2}{|c|}{1251.6} & \multicolumn{2}{|c|}{1284.5} & \multicolumn{2}{|c|}{1324.5} & 1315.9 & 1249.5 \\
\hline Density, $\mathrm{kg} / \mathrm{m}^{3}$ & \multicolumn{2}{|c|}{$1.70 \mathrm{E}-6$} & \multicolumn{2}{|c|}{$3.48 \mathrm{E}-6$} & \multicolumn{2}{|c|}{$6.95 \mathrm{E}-6$} & \multicolumn{2}{|c|}{$1.34 \mathrm{E}-5$} & \multicolumn{2}{|c|}{$3.03 \mathrm{E}-5$} & \multicolumn{2}{|c|}{$1.12 \mathrm{E}-4$} & $2.25 \mathrm{E}-4$ & $4.24 \mathrm{E}-4$ \\
\hline Temperature, K & \multicolumn{2}{|c|}{179.2} & \multicolumn{2}{|c|}{188.1} & \multicolumn{2}{|c|}{192.3} & \multicolumn{2}{|c|}{197.7} & \multicolumn{2}{|c|}{203.7} & \multicolumn{2}{|c|}{221.5} & 235.2 & 248.3 \\
\hline \multicolumn{2}{|c|}{336} & \multicolumn{2}{|c|}{340} & & 4 & & $\overline{44}$ & & 49 & & 51 & & 56 & \\
\hline & 4.0 & & 0.0 & & 9.0 & & 7.0 & & 4.0 & & 3.0 & & 1.0 & \\
\hline & 27.6 & & 0.0 & & 71.3 & & 9.7 & & 2.4 & & 5.7 & & 4.8 & \\
\hline & 5 E-4 & & $3 \mathrm{E}-3$ & & $0 \mathrm{E}-3$ & & $7 \mathrm{E}-3$ & 2.46 & $6 \mathrm{E}-3$ & 2.8 & $4 \mathrm{E}-3$ & 3.7 & $4 \mathrm{E}-3$ & \\
\hline & 7.3 & & 3.6 & & 33.3 & & 3.0 & & 0.6 & & 8.6 & & 4.6 & \\
\hline
\end{tabular}

the surfaces, and no pressure gradient normal to the wall is assumed. The temperature is fixed at $300 \mathrm{~K}$ at the surface. An axisymmetric condition is imposed along the center axis.

The present calculations are performed for 15 cases at altitudes ranging from $94.0 \mathrm{~km}$ $(t=300 \mathrm{~s})$ to $41.0 \mathrm{~km}(t=356 \mathrm{~s})$, as listed in Table 2 . The inflow parameters such as the freestream velocity, density, and temperature are given according to these flight conditions. The computational grid system of the initial state at an altitude of $58.9 \mathrm{~km}$ is shown in Fig. 8, although different grid systems are used for each altitude.

\subsubsection{Membrane deformation}

A membrane aeroshell generally deforms due to the aerodynamic force during atmospheric flight [28]. In the present paper, this membrane deformation is expressed using a particlebased model. It is assumed that the membrane consists of virtual particles, with springs connecting the particles. The virtual particle position $(\mathbf{r})$ can be described using the following equation of motion:

$$
\rho h_{0} S_{0} \frac{d^{2} \mathbf{r}}{d t^{2}}=\mathbf{F}_{\mathrm{E}}+\mathbf{F}_{\mathrm{A}},
$$

where the $(j+1 / 2)$ th components of the elastic force $\mathbf{F}_{\mathrm{E}}$ and aerodynamic force $\mathbf{F}_{\mathrm{A}}$ are respectively given by

$$
\begin{aligned}
& F_{\mathrm{E}, j+1 / 2}=E h_{j+1 / 2} l_{j+1 / 2} \frac{\varepsilon_{j(j+1 / 2)}+\nu \varepsilon_{k(j+1 / 2)}}{1-\nu^{2}}, \\
& F_{\mathrm{A}, j+1 / 2}=p_{j+1 / 2} S_{j+1 / 2} .
\end{aligned}
$$

Strains $\varepsilon$ are expressed with length $l_{j}$ and initial length $l_{j 0}$ between virtual particles as

$$
\begin{aligned}
& \varepsilon_{j(j+1 / 2)}=\frac{l_{j(j+1 / 2)}-l_{j 0(j+1 / 2)}}{l_{j 0(j+1 / 2)}}, \\
& \varepsilon_{k(j+1 / 2)}=\frac{l_{k(j+1 / 2)}-l_{k 0(j+1 / 2)}}{l_{j 0(j+1 / 2)}},
\end{aligned}
$$

The Young's modulus $E$ and Poisson's ratio $\nu$ of the ZYLON were set to $30 \mathrm{MPa}$ and 0.3 , respectively. These parameters are tuned so that the stretch of the aeroshell because of the 


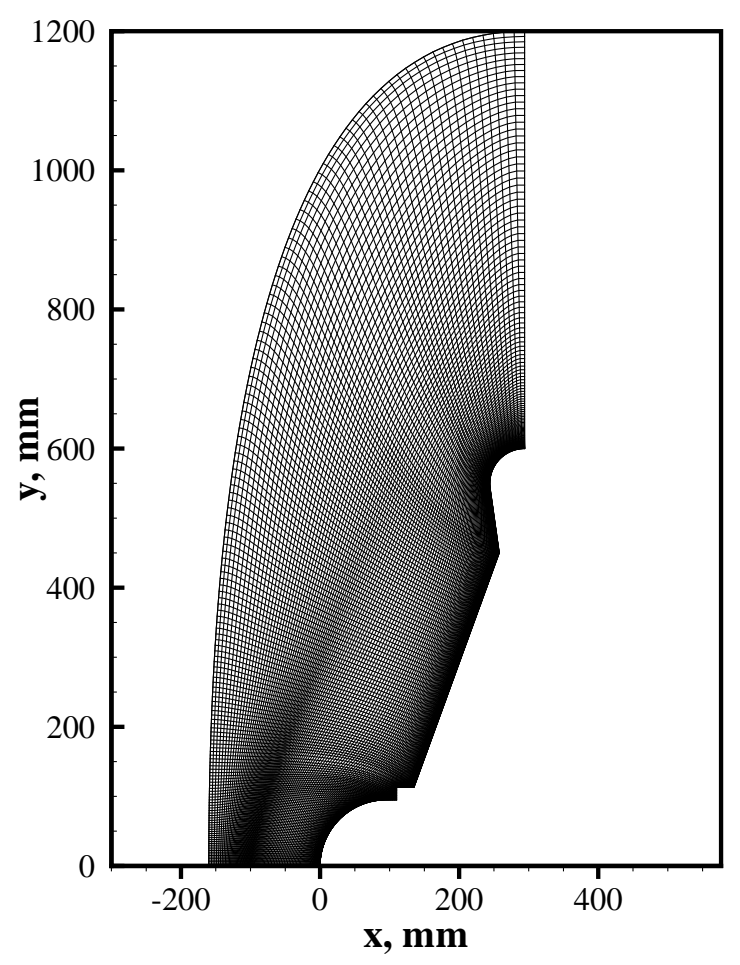

Figure 8: Computational grid system at an altitude of $58.9 \mathrm{~km}$.

membrane deformation corresponds to the flight experimental results which were constructed based on the images taken by onboard JPEG cameras mounted on the backside of the SMAAC [18]. Thus, the textile properties of the aeroshell are assumed to be isotropic. The density is the same as that listed in Table 1 . Parameter $C_{\mathrm{AE}}$, which represents the ratio of the aerodynamic force to the elastic force of the membrane, is defined by

$$
C_{\mathrm{AE}}=\frac{\rho_{\infty} U_{\infty}^{2} L}{E h_{0}}
$$

where the thickness of the ZYLON fabric $h_{0}$ is $0.155 \mathrm{~mm}$. Thus, the $C_{\mathrm{AE}}$ value of the SMAAC is on the order of $10^{-1}$ during aerodynamic heating.

The equation of motion is solved using the 4th order Runge-Kutta method. As the boundary, the displacement is fixed on the capsule-side end. The free-end condition on the side of the torus is set in the $x$ direction, and the fixed-end condition is set in the $y$ direction. The flow field is simulated coupled with the membrane deformation.

\section{Results and Discussion}

\subsection{Validation of heat conduction model}

The temperature history measured by the TC1 thermocouples on the membrane aeroshell during the SMAAC atmospheric reentry is shown in Fig. 9. The histories measured by six other thermocouples (TC2, TC3, and TC5-TC8) show tendencies similar to that by TC1, and 


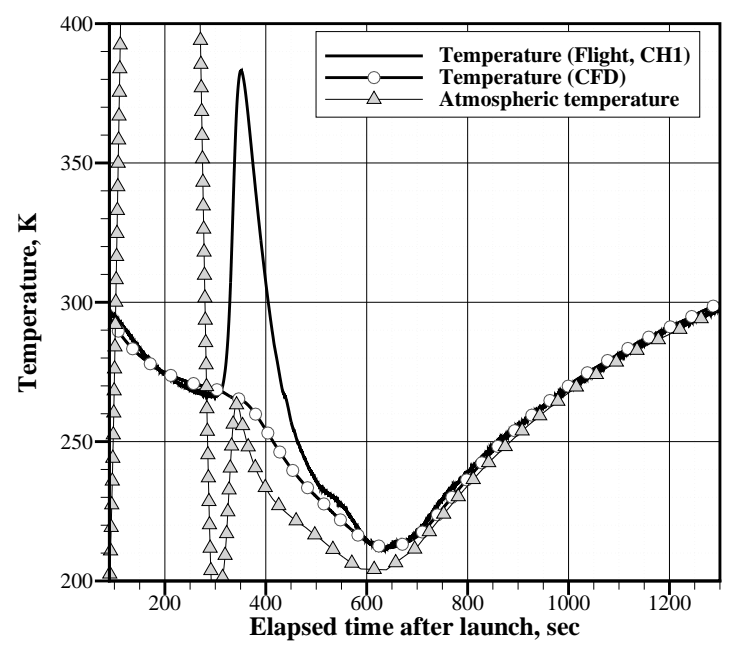

Figure 9: Histories of measured and predicted temperatures without aerodynamic heating and atmospheric temperature.

these profiles are shown in the appendix. This figure includes the atmospheric temperature and temperature profile calculated by the heat conduction model on the membrane of the SMAAC without aerodynamic heating $\left(q_{\mathrm{conv}}=0\right)$, to validate the model factors (i.e., the solar radiation coefficient " $a_{\text {solar }}$ " and heat transfer coefficient " $h$ ") in the heat conduction model. Based on this history, the elapsed time after launch at which the temperature at the membrane reaches its peak value is about $350 \mathrm{~s}$, and its peak temperature is about $380 \mathrm{~K}$.

We estimate that aerodynamic heating occurs from $t=300$ to $t=350 \mathrm{~s}$. At higher altitudes, the membrane is cooled by blackbody radiation. After aerodynamic heating, the measured temperature rapidly decreases due to this blackbody radiation, in addition to the forced convection. On the other hand, the membranes are only equilibrated with the atmospheric temperature by the forced convection at lower altitudes. The predicted temperature shows good agreement with the measured temperature, except for the aerodynamic heat duration. This indicates that the parameters of the heat conduction model adequately describe the experimental environment. In the present paper, the convective heat flux by aerodynamic heating is calculated using the computational fluid dynamics (CFD).

\subsection{Aerodynamic heating prediction}

Numerical simulations of the flow fields during aerodynamic heating were performed for the 15 altitudes listed in Table 2. The Reynolds number of the flow field ranges from $10^{4}$ to $10^{5}$ when strong aerodynamic heating occurs. Thus, the flow field is expected to transition from a laminar to turbulent flow during reentry. In the present study, simulations of the laminar and turbulent cases were performed, and their results are compared with the measured temperature histories. The heat flux profiles predicted by the CFD technique are shown in this section.

Figures 10(a), 10(b), 10(c), and 10(d) show the temperature distributions with stream traces for the laminar and turbulent (SST model) cases without/with the membrane deformation model at an altitude of $58.9 \mathrm{~km}$. It is confirmed that a shock wave is formed in 
front of the vehicle, where the temperature becomes uniformly constant from the capsule to the torus. In addition, Figs. 11(a) and 11(b) show comparisons of the heat flux profiles along the SMAAC surface between the laminar and turbulent cases at an altitude of $58.9 \mathrm{~km}$ without/with the membrane deformation model, respectively.

The membrane is largely deformed by the aerodynamic force when considering the membrane deformation model. In contrast with a rigid vehicle such as a conventional reentry capsule, the membrane aeroshell of an inflatable vehicle such as the SMAAC can be deformed during flight. It is expected that the deformation model used in the numerical simulation can have an influence on the prediction of the heat flux on the membrane surface. The heat flux on the membrane surface with the deformation model becomes low compared with the rigid model. On the other hand, the heat flux on the capsule with the deformation model only changes slightly. This is mainly because the shock stand-off distance near the stagnation line shortens. These features are attributed to the shock layer formation, with the deformation effect that the inflatable torus moves backward because of the stretching of the aeroshell, with a reduction in the effective flare angle. Thus, it is necessary to introduce a membrane deformation model when predicting the aerodynamic heating for this kind of vehicle. In the following discussions, the heat flux predicted with the membrane deformation model is used.

For the case of laminar flow, the flow in the shock layer separates on the capsule surface, and a large recirculation region appears along the overall membrane aeroshell. On the other hand, no recirculation region appears for the case of turbulent flow. This is because the turbulent viscosity (eddy viscosity) in the shock layer becomes high considering the turbulence model. This is expected to increase the heat flux on the capsule and membrane surfaces, because the temperature gradient in the spatial direction near the SMAAC surface becomes high. The heat flux at the top of the capsule become about $16.5 \mathrm{~kW} / \mathrm{m}^{2}$ for the turbulent flow case, because turbulence develops near the capsule. Note that the numerical solution of the laminar flow is smaller than the heat flux based on the empirical model that has been used for the design of the SMAAC. For the case of laminar flow, there is high heat flux on a joint part between the membrane aeroshell and inflatable torus positions at the reattachment point of the recirculation region. However, in most regions of the membrane, the heat flux remains relatively low, because the high-temperature gas in the shock layer hardly inflows to the recirculation region. On the other hand, for the case of turbulent flow, the heat flux distribution on the membrane from the capsule side to the torus side is almost constant. As confirmed in the heat flux profile for the laminar flow, an obvious reattachment point is not seen for the turbulence flow case. The strong diffusivity of the turbulence causes hightemperature gas to flow into the recirculation region. As a result, the heat flux profile along the membrane surface considering the turbulence model becomes smooth.

A predictive tool of aerodynamic heating and the thermal environment around the inflatable vehicle was reconstructed for suborbital reentry. However, for orbital speed reentry (more than $7 \mathrm{~km} / \mathrm{s}$ ) from a low Earth orbit, further development of the predictive tool is required. Because the Mach number in orbital reentry becomes higher than that of the suborbital reentry, real gas effects, e.g., chemical reactions, excitation of internal energy, and energy transfer, can occur at certain altitudes. These effects are neglected in the predictive tool of aerodynamic heating. However, the present tool can be effective for thermal environment prediction at higher and lower altitudes before and after aerodynamic heating. The membrane aeroshell and inflatable torus are anisotropic, and the isotropic analysis conducted is generally insufficient, as reported in Ref. [9]. Although an isotropic analysis can be effective at an initial stage of design, introduction of an orthotropic analysis may be needed for the accurate prediction of membrane deformation. 


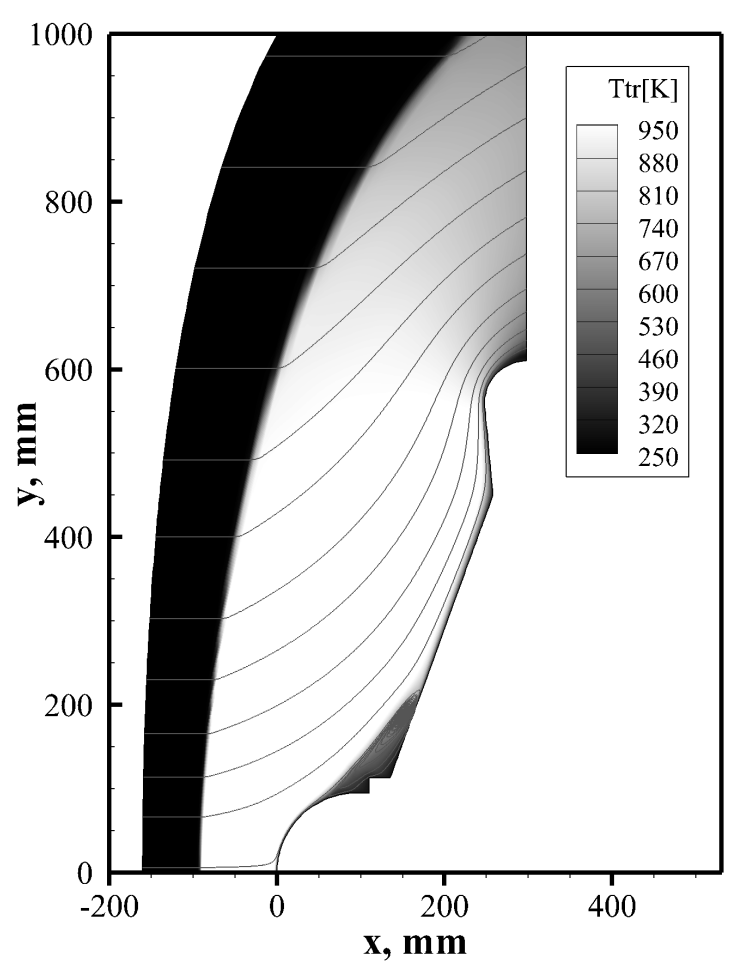

(a) Laminar case without deformation model.

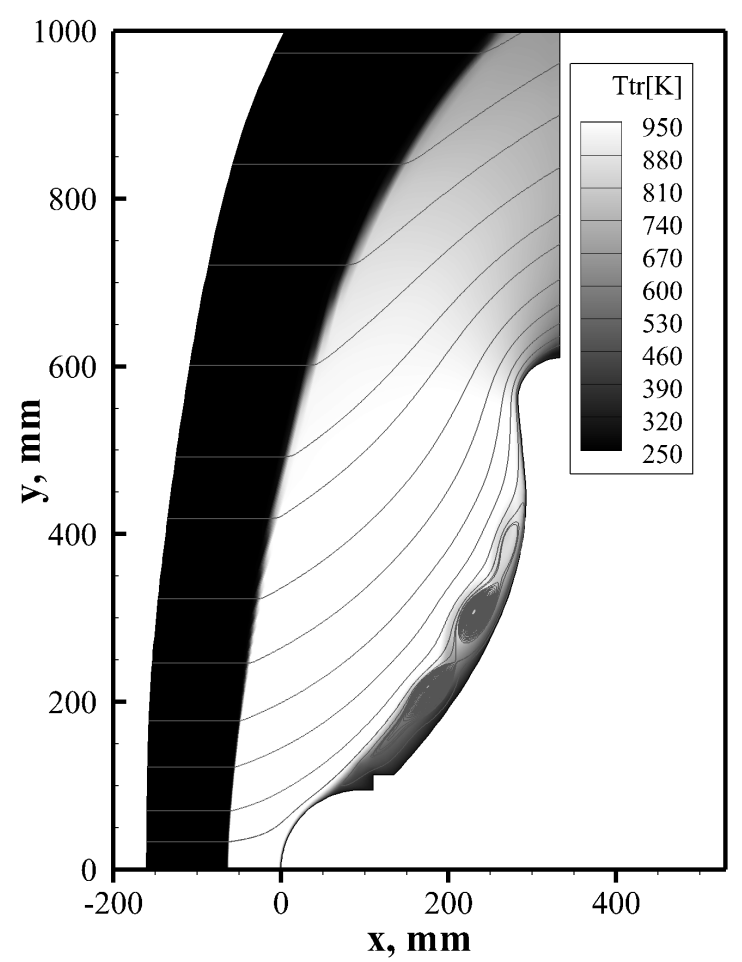

(c) Laminar case with deformation model.

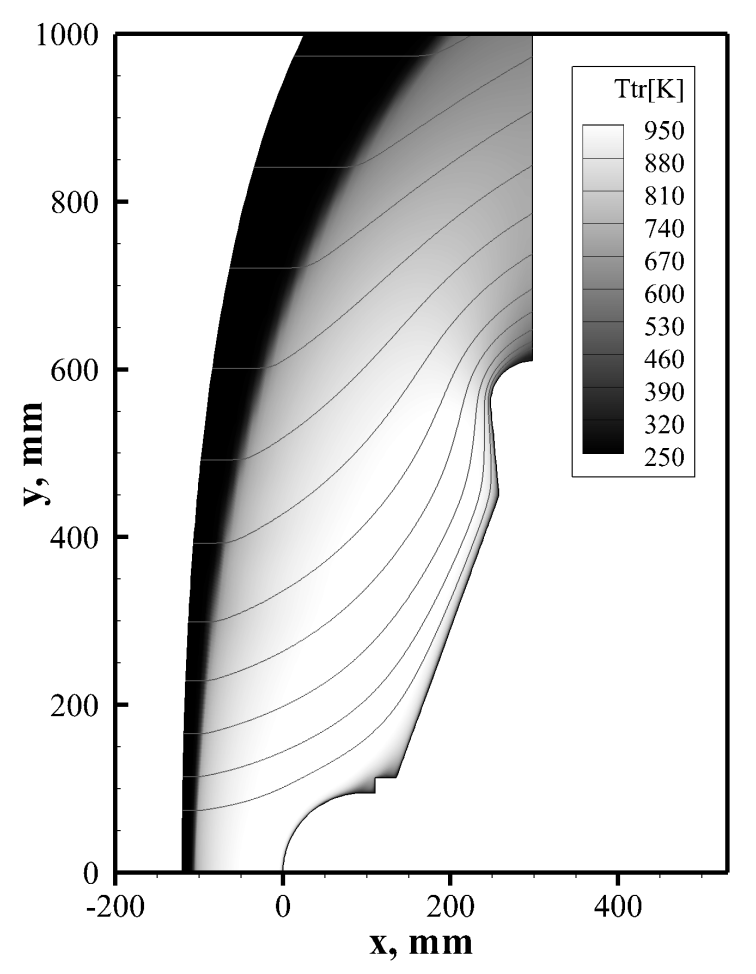

(b) Turbulent case without deformation model.

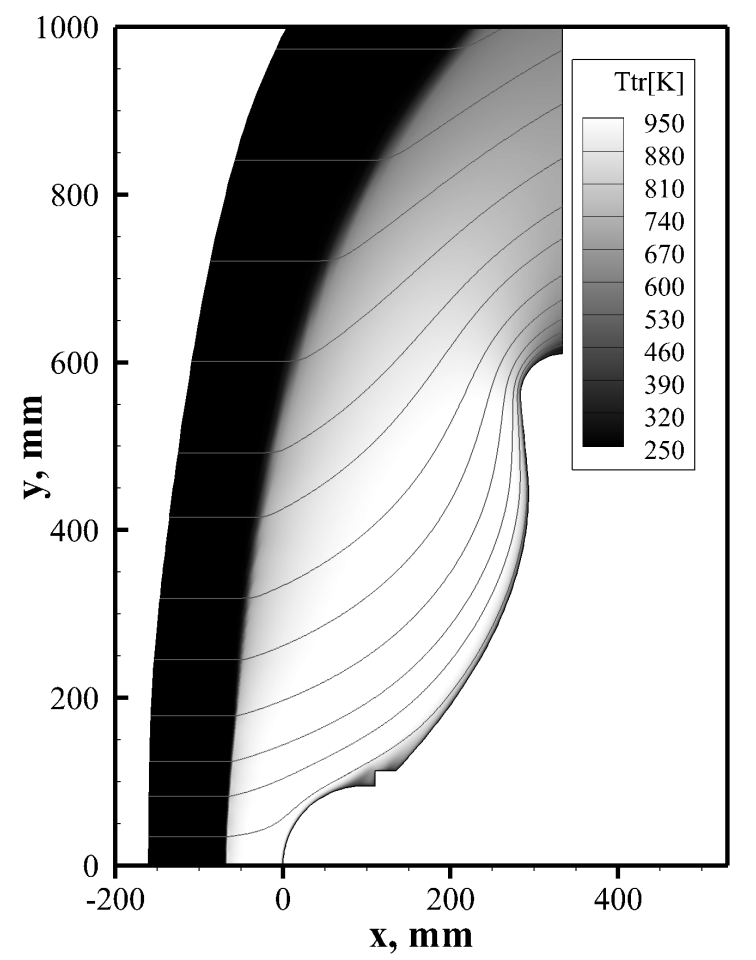

(d) Turbulent case with deformation model.

Figure 10: Distributions of temperature and stream traces around SMAAC at altitude of $58.9 \mathrm{~km}$. 


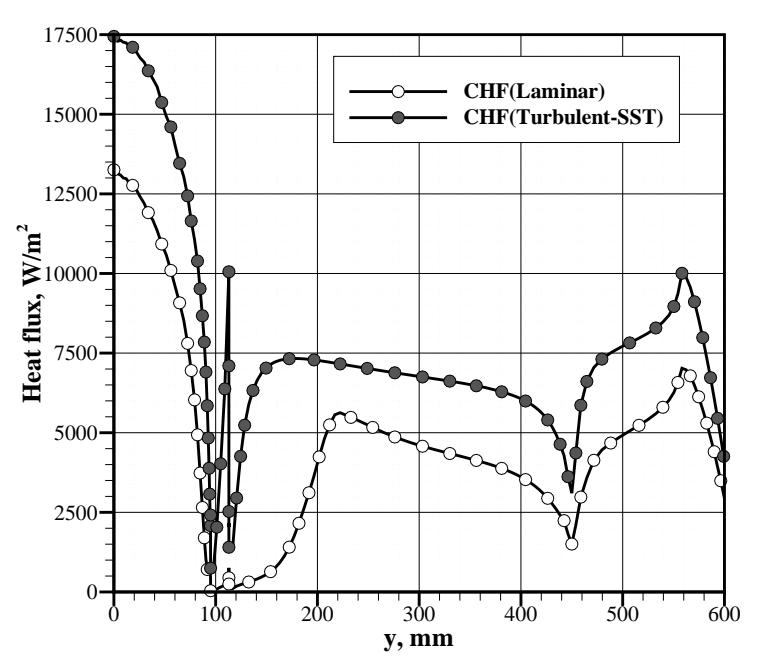

(a) Without membrane deformation model

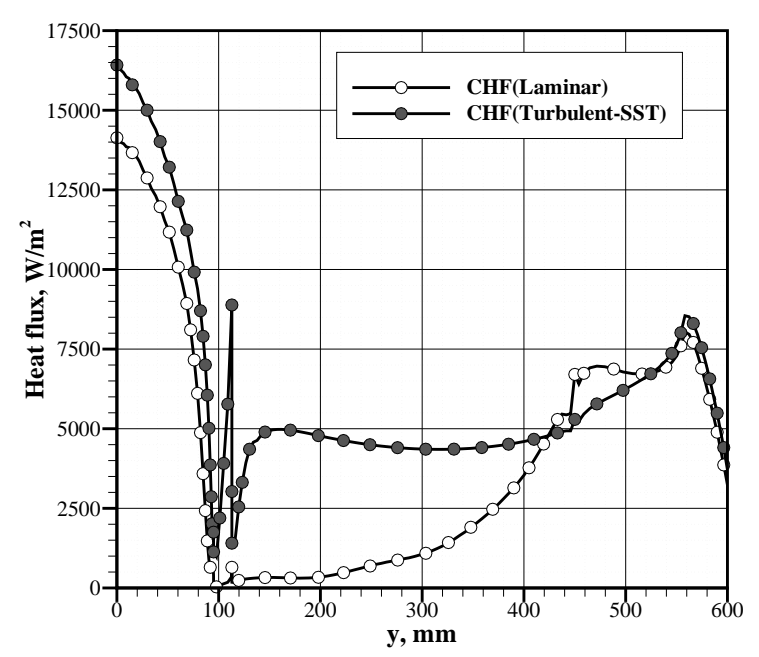

(b) With membrane deformation model

Figure 11: Comparison of radial profiles of convective heat fluxes on SMAAC surface between laminar and turbulent cases at altitude of $58.9 \mathrm{~km}$.

\subsection{Thermal behavior of capsule}

The heat conductions in the capsule part are investigated using the experimental data and simulation results with the deformation for the laminar and turbulent cases. Figures 12(a) and 12(b) show comparisons of these at the backside of the semi-spherical shell of the aluminum capsule. Measured temperature increases of approximately $20 \mathrm{~K}$ are observed. The temperature reaches the maximum value of $315 \mathrm{~K}$ for the aluminum capsule. The increases in temperature are due to aerodynamic heating during the elapsed time period of $350 \mathrm{~s}$ to $400 \mathrm{~s}$. Then, the capsule is cooled by the atmosphere.

For the aluminum capsule, the predicted temperatures for the case of laminar flow show good agreement with the measured temperatures. On the other hand, for the case of turbulence, the predicted temperatures tend to overestimate the measured temperatures. It is possible that the distance travelled by the flow on the capsule surface is too short to transition to turbulence. Thus, if the flow near the capsule is laminar, a reasonable agreement is obtained. In this case, the maximum heat flux at the stagnation point is expected to be about $14 \mathrm{~kW} / \mathrm{m}^{2}$ during the reentry flight.

\subsection{Thermal behavior of membrane}

Figure 13 show comparisons of the measured and predicted temperatures at thermocouples positions TC1, TC2, and TC5. This figure includes the heat flux histories predicted by the CFD with the deformation model. Similar to the capsule, the membrane is heated by aerodynamic heating. These temperature profiles are similar to the profiles at the other thermocouples, which are shown in the appendix. The maximum temperature is $380 \mathrm{~K}$ at an elapsed time of approximately $350 \mathrm{~s}$. Compared with the measured temperatures, the elapsed times needed to reach the peak temperatures with the numerical method are short. As mentioned above, the time scale for the heat conduction of the membrane is approximately 3-4 s. This is mainly due to neglecting the temperature gradient in the spatial direction in the heat conduction model. The temperature histories measured with thermocouples TC1, TC2, 


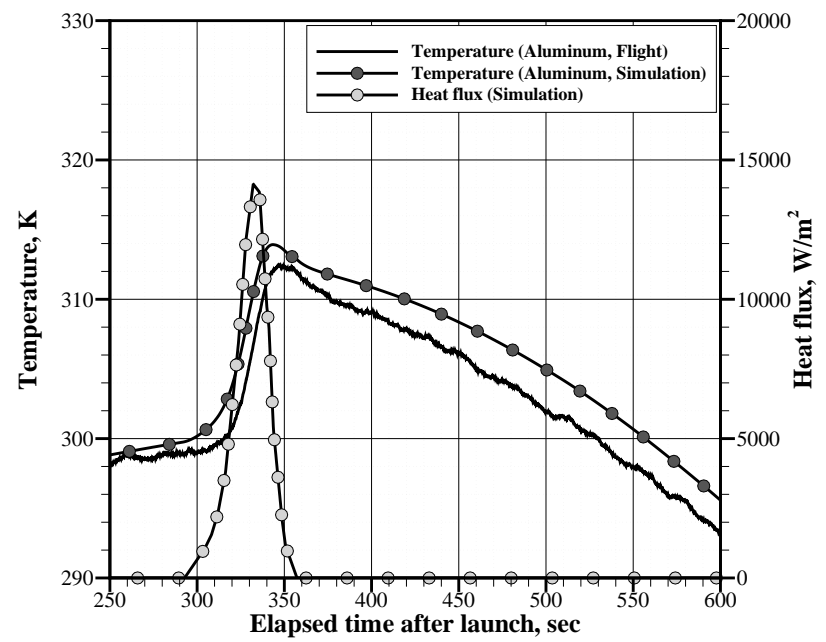

(a) Laminar case.

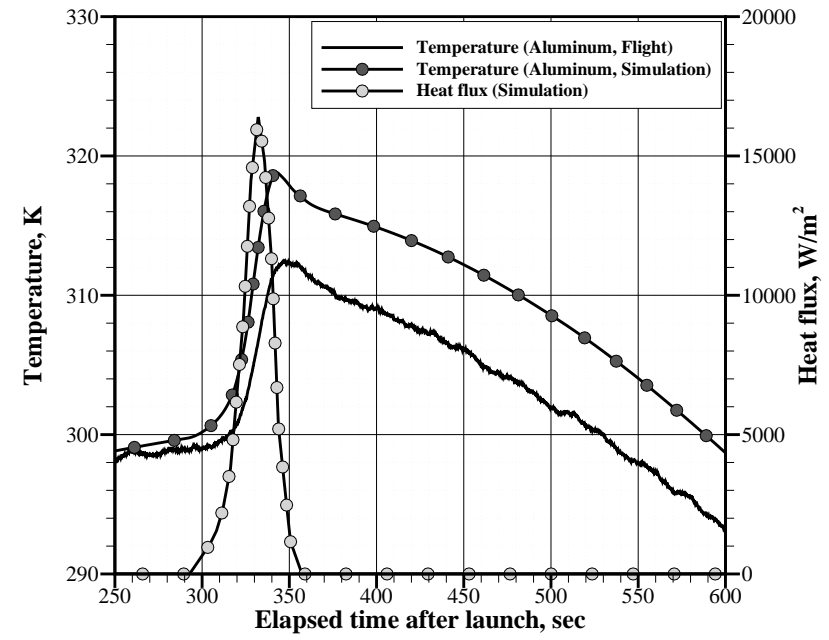

(b) Turbulent case.

Figure 12: Histories of measured and predicted temperatures and heat fluxes at backside of semi-spherical shell of aluminum capsule.

and TC5 are very similar to each other. The phases of the three thermocouples positions are respectively different, as shown in Fig. 2, while the radii of the mounting positions are close (TC1: $y=254 \mathrm{~mm}$, TC2: $y=273 \mathrm{~mm}$, and TC5: $y=254 \mathrm{~mm}$ ). It was reported by Nagata et al. [20] that the SMAAC vehicle flew at the angle of attack during aerodynamic heating. On the other hand, the vehicle had an angular velocity around the symmetrical body axis. It was reasonable to use a time-averaged heat flux on the membrane surface in the circumferential direction, and the temperature profiles became almost constant in this direction.

Comparisons of the measured and predicted temperature distributions in the radial direction on the membrane for elapsed times of 300,348 , and $380 \mathrm{~s}$ at each thermocouples are shown in Fig. 14. A feature of the measured temperature distribution is an almost constant profile for each thermocouples. Because the membrane is thin, its heat conduction in the radial direction is never dominant compared with that in the thickness direction. This means that the heat flux profile along the membrane surface for the flight is also constant during the aerodynamic heating. Compared with the measured temperature, for the laminar flow calculation, the predicted temperatures at the thermocouples near the capsule side (e.g., TC3 and TC6) become low due to the presence of the recirculation region. On the other hand, for the case of the turbulent flow in the prediction, no recirculation region appears, and the heat flux shows a uniform distribution on the membrane. It is suggested that the heat fluxes at each point where the thermocouples are mounted are in the same range, as indicated by the measured temperature profiles shown in Fig. 14. The temperatures predicted with the turbulent model show qualitatively good agreement with the measured temperatures. Hence, it is reasonable to conclude that there is no recirculation region in the shock layer, and the flow field near the membrane surface is turbulent during aerodynamic heating in the flight.

A feature of the aerodynamic heating around the SMAAC is that the heat flux profiles are almost constant in the circumferential and radial directions. This is thought to be because the flow field is temporally averaged by the angular velocity and is turbulent. In addition, a comparison of the measured and predicted temperature histories suggests that the peak heat 


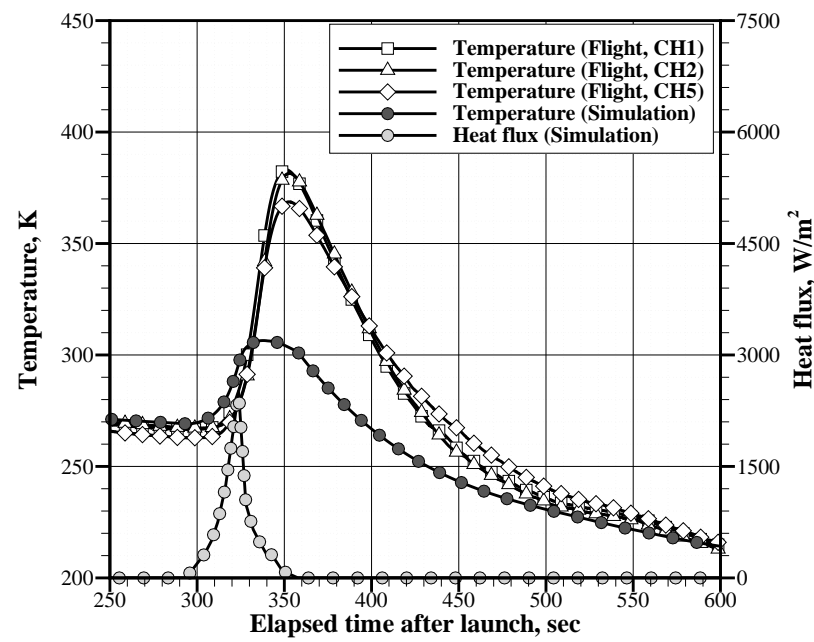

(a) Laminar case

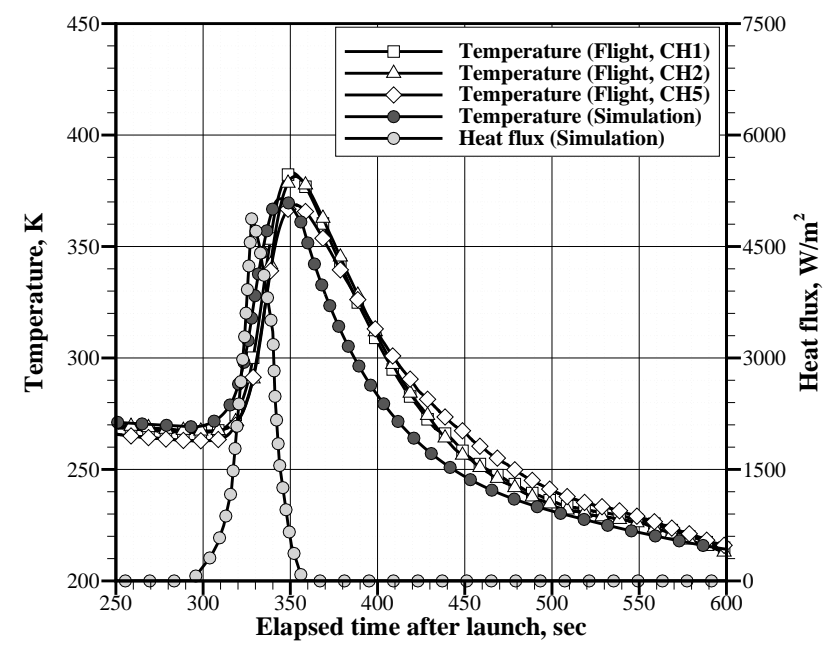

(b) Turbulent case

Figure 13: Histories of measured and predicted temperatures and heat fluxes at TC1, TC2, and TC5 positions.

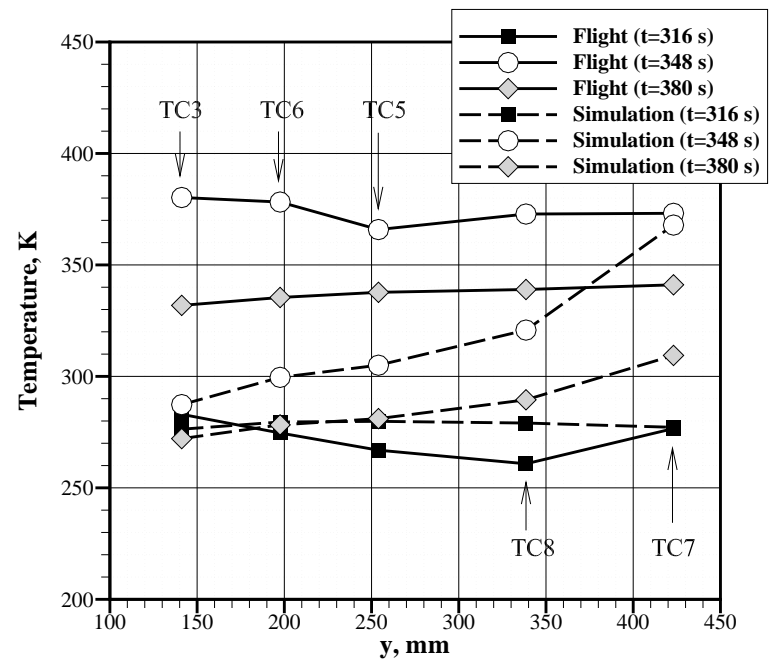

(a) Laminar case

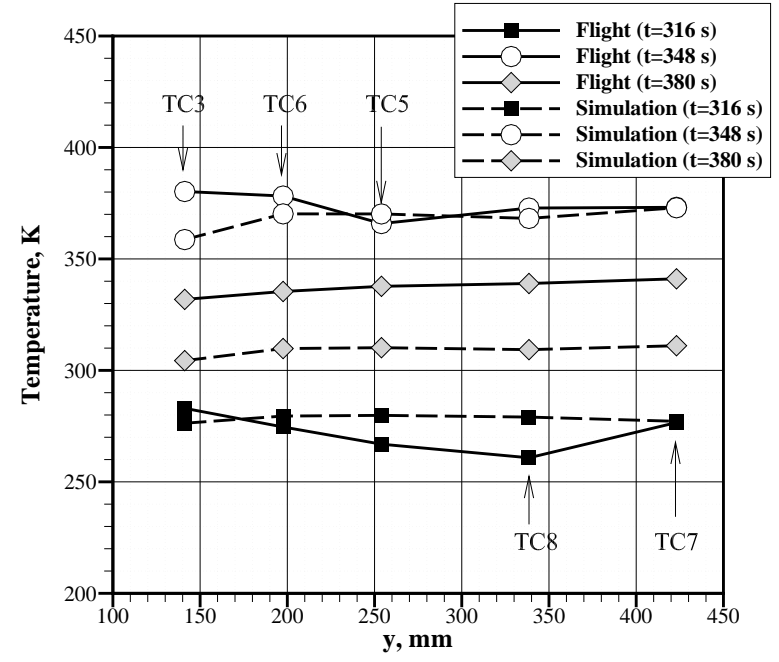

(b) Turbulent case

Figure 14: Comparison of measured and predicted temperature distributions on membrane. 
flux on the membrane is more than $5 \mathrm{~kW} / \mathrm{m}^{2}$.

\section{Conclusions}

A suborbital reentry demonstration of an inflatable vehicle using a sounding rocket was successfully performed. The temperature histories were measured using seven thermocouples embedded on the backside of a membrane aeroshell. In addition, the temperature profile at the backside of the semi-spherical shell of the aluminum capsule was obtained using a temperature transducer. To investigate the aerodynamic heating behavior around the inflatable vehicle during atmospheric reentry, the measured temperatures were compared with the temperatures obtained using an unsteady heat conduction equation. The heat fluxes by aerodynamic heating that were used as the input parameters of the heat conduction model were predicted for cases of laminar and turbulent flows with the simulation model using computational fluid dynamics. Using the reentry trajectory reconstructed based on the measured data and an atmospheric model, flow-field simulations were performed for 15 cases, including a freestream condition for an altitude. On the membrane aeroshell, the predicted temperature histories for the case of turbulent flow showed good agreement with the measured temperatures, while those for the laminar flow were generally underestimated because of the recirculation region and lower heat flux. On the other hand, the predicted temperature on the capsule for the case of laminar flow showed good agreement with the experimental data. It was suggested that the flow field near the capsule surface was possibly laminar, and then transitioned into turbulence on the membrane during aerodynamic heating. These results suggested that an aerodynamic heating reduction was demonstrated by the low-ballistic-coefficient flight of the thin-membrane inflatable vehicle.

\section{Appendix}

Comparisons of measured and predicted temperatures at positions of thermocouples TC3, TC6, TC7, and TC8 are shown in Figs. 15, 16, 17, and 18, respectively.

\section{Acknowledgments}

The sounding rocket experiment was carried out at the Uchinoura Space Center (USC) in collaboration with the Research and Operation Office for Sounding Rocket (ROOSR) at the Japan Aerospace Exploration Agency. This research activity was also supported by the Steering Committees for Space Engineering (SCSE). We would like to thank the members of ROOSR, USC, and SCSE for their useful advice and support.

The computation was mainly carried out using the computer facilities at the Research Institute for Information Technology, Kyushu University.

\section{References}

[1] M. Gräßilin and U. Schöttle. "Flight Performance Evaluation of the Reentry Mission IRDT-1". In Papers Presented at the 52nd International Astronautical Congress, IAF Paper 01-V305, Toulouse, France, October 1 - 52001. 
[2] S.J. Hughes, R.A. Dillman, B.R. Starr, R.A. Stephan, M.C. Lindell, C.J. Player, and D.F.M. Cheatwood. "Inflatable Re-entry Vehicle Experiment (IRVE) Design Overview". AIAA Paper 2005-1636, 2005.

[3] R.R. Rohrschneider and R.D. Braun. "A Survey of Ballute Technology for Aerocapture". Journal of Spacecraft and Rockets, 44(1):10-23, January - February 2007.

[4] P. Reynier and D. Evans. "Postflight Analysis of Inflatable Reentry and Descent Technology Blackout During Earth Reentry". Journal of Spacecraft and Rockets, 46(4):800-809, July-August 2009.

[5] S.J. Hughes, D.F.M. Cheatwood, A.M. Calomino, and H.S. Wright. "Hypersonic Inflatable Aerodynamic Decelerator (HIAD) Technology Development Overview". AIAA Paper 2011-2524, 2011.

[6] T. Abe. "A Self-Consistent Tension Shell Structure for Application to Aerobraking Vehicle and Its Aerodynamic Characteristics". AIAA Paper 1988-3405, 1988.

[7] I.G. Clark, A.L. Hutchings, C.L. Tanner, and R.D. Braun. "Supersonic Inflatable Aerodynamic Decelerators for Use on Future Robotic Missions to Mars". Journal of Spacecraft and Rockets, 46(2):340-352, March - April 2009.

[8] I.G. Clark. Aerodynamic Design, Analysis, and Validation of a Supersonic Inflatable Decelerator. PhD thesis, Georgia Institude of Technology, july 2009.

[9] C.L. Tanner. Aeroelastic Analysis and Testing of Supersonic Inflatable Aerodynamic Decelerators. PhD thesis, Georgia Institude of Technology, May 2012.

[10] K. Yamada, D. Akita, E. Sato, K. Suzuki, T. Narumi, and T. Abe. "Flare-Type Membrane Aeroshell Flight Test at Free Drop from a Balloon". Journal of Spacecraft and Rockets, 46(3):606-614, May-June 2009.

[11] K. Yamada, T. Abe, K. Suzuki, N. Honma, M. Koyama, Y. Nagata, D. Abe, Y. Kimura, A.K. Hayashi, D. Akita, and H. Makino. "Deployment and Flight Test of Inflatable Membrane Aeroshell using Large Scientific Balloon". AIAA Paper 2011-2579, 2011.

[12] K. Yamada, M. Koyama, Y. Kimura, K. Suzuki, T. Abe, and A.K. Hayashi. "Hypersonic Wind Tunnel Test of a Flare-type Membrane Aeroshell for Atmospheric Entry Capsule". ISTS Special Issue: Selected papers from the 27th ISTS, Transactions of JSASS, 7(ists27):27-32, 2010.

[13] K. Yamada, T. Sonoda, K. Nakashino, and T. Abe. "Structural Strength of Flare-type Membrane Aeroshell Supported by Inflatable Tours against Aerodynamic Force". In Proceedings of 28th International Symposium on Space Technology and Science, ISTS 2011-c-34, Okinawa, Japan, June 5 - 122011.

[14] Y. Takahashi, K. Yamada, and T. Abe. "Radio Frequency Blackout Possibility for an Inflatable Reentry Vehicle". AIAA Paper 2012-3110, 2012.

[15] Y. Takahashi, K. Yamada, and T. Abe. "Examination of Radio Frequency Blackout for an Inflatable Vehicle during Atmospheric Reentry". Journal of Spacecraft and Rockets, 51(2):430-441, March 2014. 
[16] K. Yamada, T. Abe, K. Suzuki, O. Imamura, and D. Akita. "Reentry Demonstration Plan of Flare-type Membrane Aeroshell for Atmospheric Entry Vehicle using a Sounding Rocket". AIAA Paper 2011-2521, 2011.

[17] K. Yamada, Y. Nagata, T. Abe, K. Suzuki, O. Imamura, and D. Akita. "Suborbital Reentry Demonstration of Inflatable Flare-Type Thin-Membrane Aeroshell Using a Sounding Rocket". Journal of Spacecraft and Rockets, 52(1):275-284, February-March 2015.

[18] K. Yamada, Y. Nagata, T. Abe, K. Suzuki, O. Imamura, and D. Akita. "Reentry Demonstration of Flare-type Membrane Aeroshell for Atmospheric Entry Vehicle using a Sounding Rocket". AIAA Paper 2013-1388, 2013.

[19] K. Yamada, Y. Nagata, N. Honma, D. Akita, O. Imamura, T. Abe, and K. Suzuki. "Reentry Demonstration Deployable and Flexible Aeroshell for Atmospheric-Entry Vehicle using Sounding Rocket". In Proceedings of 63th International Astronautical Congress, AC-12-D2.3.3, Naples, Italy, October 1 - 52012.

[20] Y. Nagata, K. Yamada, T. Abe, and k Suzuki. "Attitude Dynamics for Flare-type Membrane Aeroshell Capsule in Reentry Flight Experiment". AIAA Paper 2013-1285, 2013.

[21] C.G. Justus and D.L. Johnson. "NASA/MSFC Global Reference Atmospheric Model1999 Version (GRAM-99)". NASA TM-1999-209630, May 1999.

[22] L.A. Carlson and W.J. Horn. "New Thermal and Trajectory Model for High-Altitude Balloons". Journal of Aircraft, 20(6):500-507, June 1983.

[23] J.M. Yos. "Transport Properties of Nitrogen, Hydrogen Oxygen and Air to 30,000 K". TRAD-TM-63-7, Research and Advanced Development Division, AVCO Corp., 1963.

[24] R.N. Gupta, J.M. Yos, R.A. Thompson, and K.P. Lee. "A Review of Reaction Rates and Thermodynamic and Transport Properties for an 11-Species Air Model for Chemical and Thermal Nonequilibrium Calculations to 30000 K". NASA RP-1232, Aug. 1990.

[25] F.R. Menter. "Two-Equation Eddy-Viscosity Turbulence Models for Engineering Applications". AIAA Journal, 32(8):1598-1605, August 1994.

[26] E. Shima and K. Kitamura. "Parameter-Free Simple Low-Dissipation AUSM-Family Scheme for All Speeds". AIAA Journal, 49(8):1693-1709, August 2011.

[27] A. Jameson and S. Yoon. "Lower-Upper Implicit Schemes with Multiple Grids for the Euler Equations". AIAA Journal, 25(7):929-935, July 1987.

[28] K. Yamada, Y. Kato, and T. Abe. "Numerical Simulation of Hypersonic Flow around Flare-Type Aeroshell with Torus Frame". In Proceedings of $6^{\text {th }}$ Asia Workshop on Computational Fluid Dynamics, Kashiwa, Japan, March 162009. 


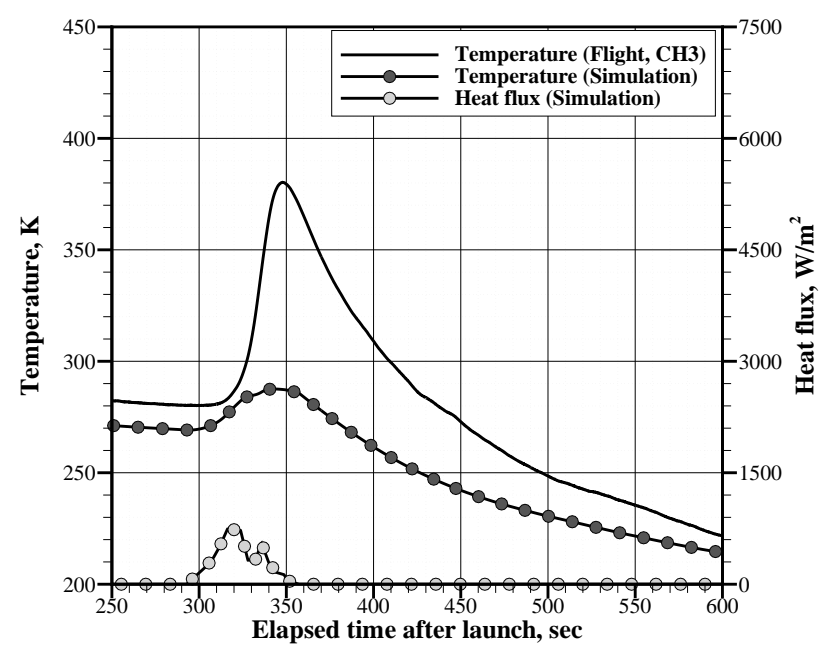

(a) Laminar case

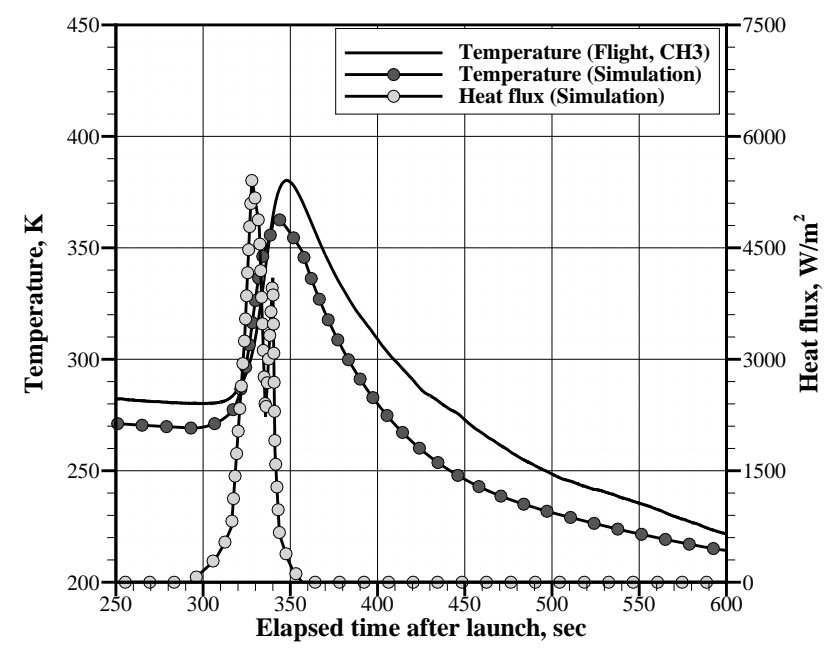

(b) Turbulent case

Figure 15: Histories of measured and predicted temperatures and heat fluxes at TC3 position $(y=141 \mathrm{~mm})$.

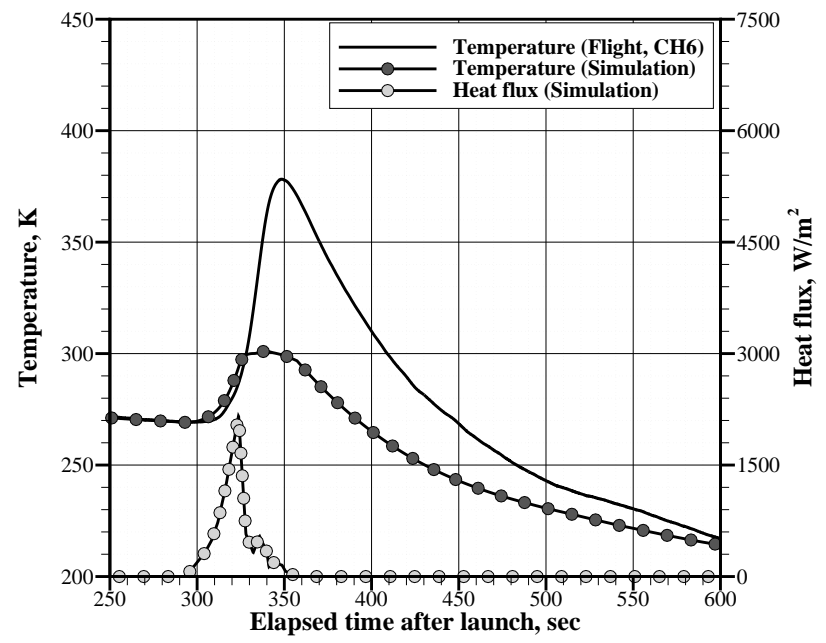

(a) Laminar case

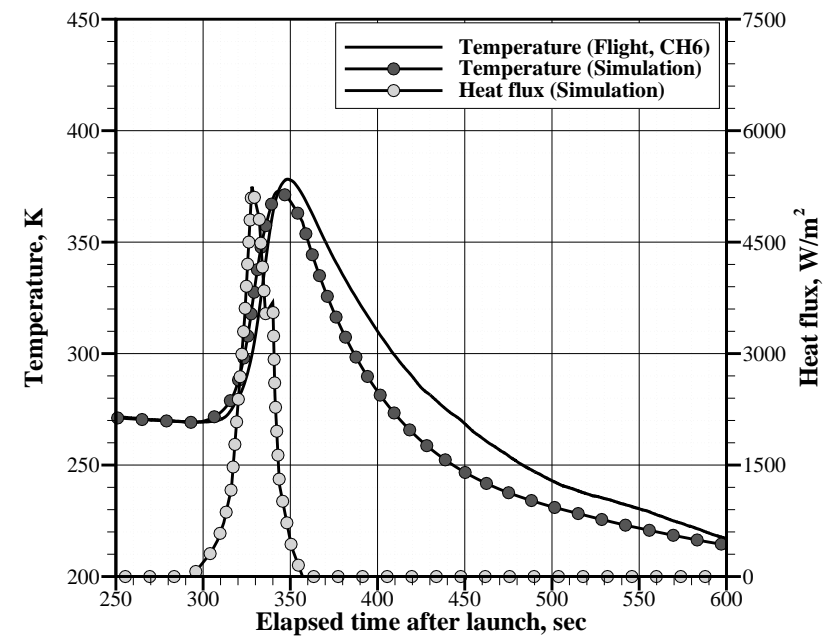

(b) Turbulent case

Figure 16: Histories of measured and predicted temperatures and heat fluxes at TC6 position $(y=198 \mathrm{~mm})$. 


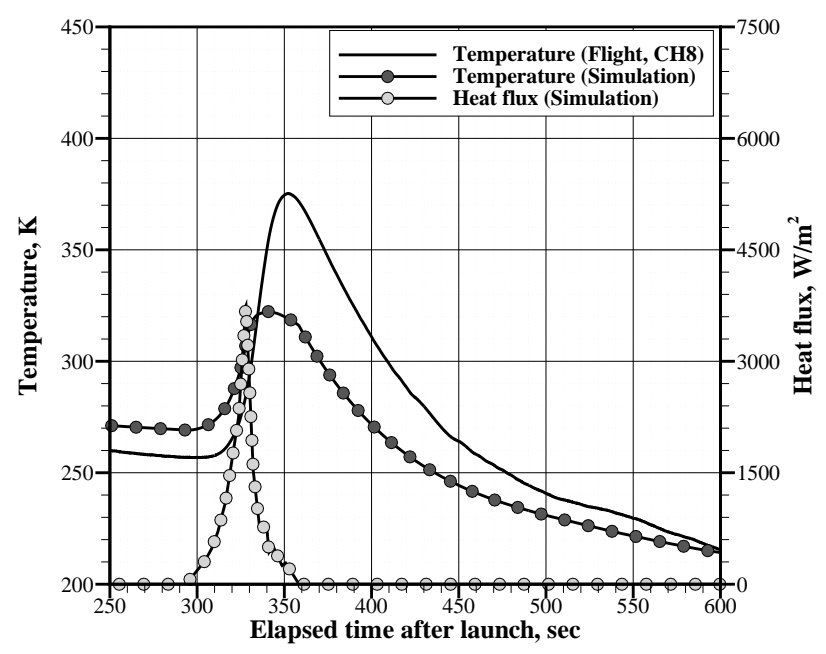

(a) Laminar case

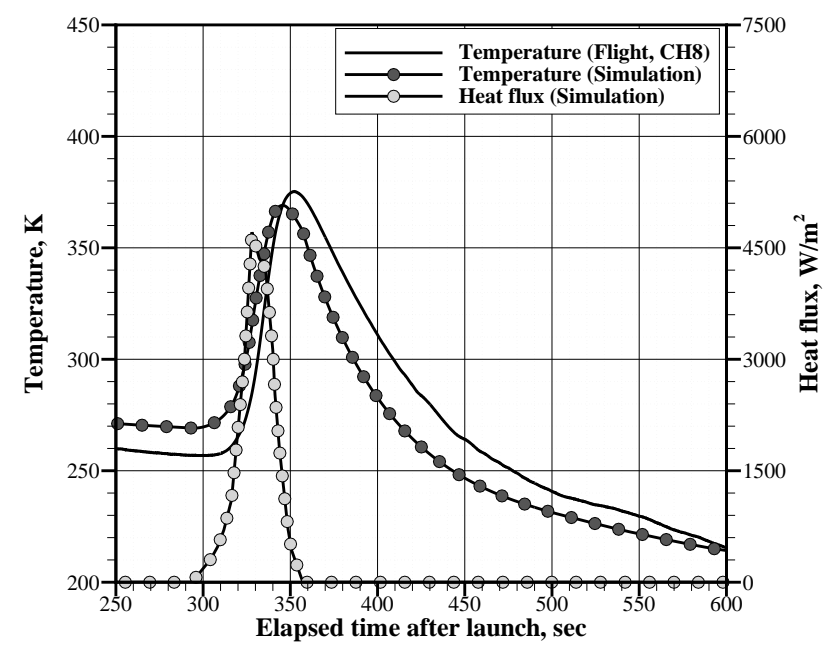

(b) Turbulent case

Figure 17: Histories of measured and predicted temperatures and heat fluxes at TC8 position $(y=339 \mathrm{~mm})$.

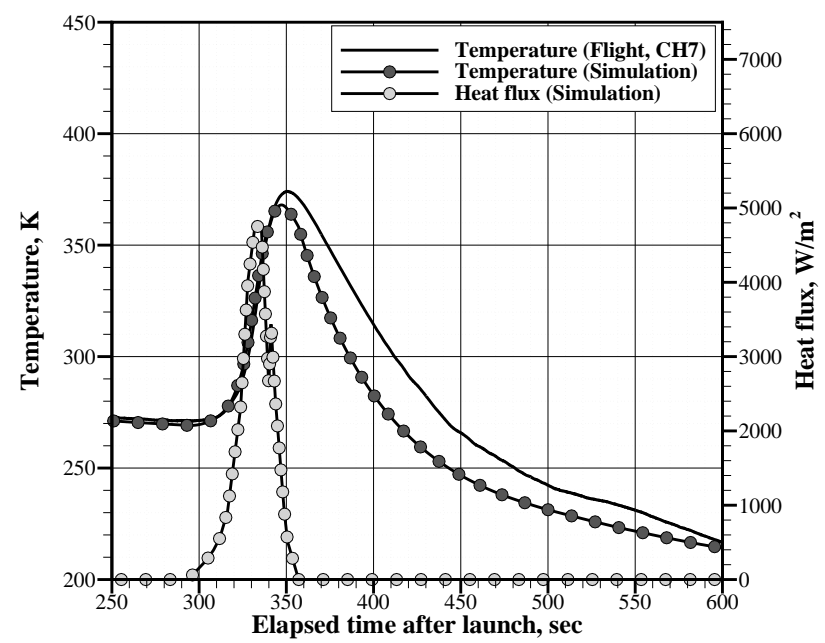

(a) Laminar case

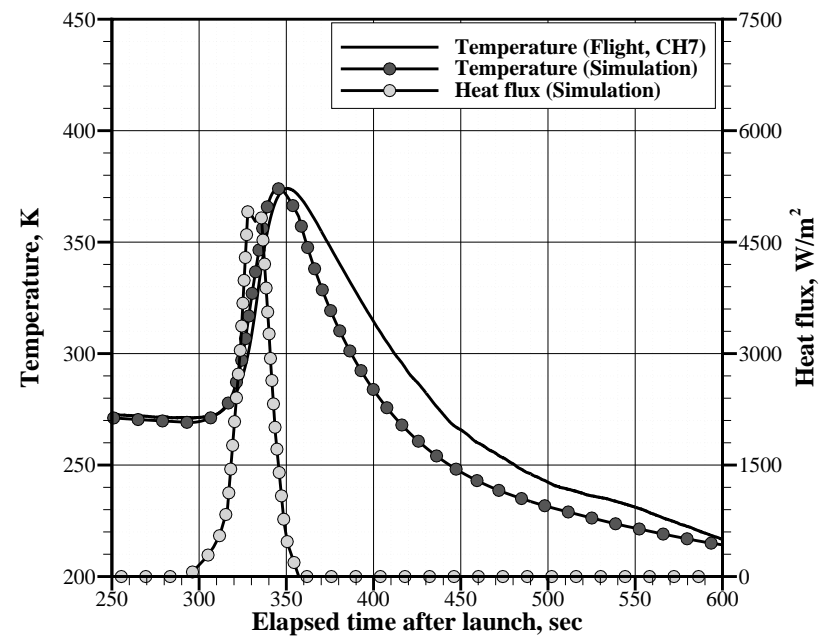

(b) Turbulent case

Figure 18: Histories of measured and predicted temperatures and heat fluxes at TC7 position $(y=423 \mathrm{~mm})$. 